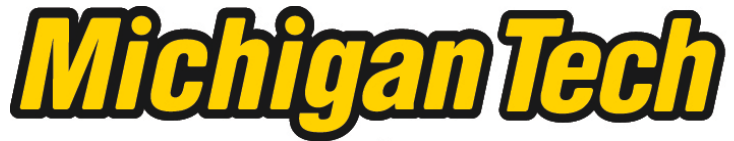 \\ Michigan Technological University Create the Future Digital Commons @ Michigan Tech
}

Dissertations, Master's Theses and Master's Reports - Open

Dissertations, Master's Theses and Master's

Reports

2011

\section{Effects of instructional changes on student learning of electrochemistry in an IB chemistry course}

Deborah Corriveau

Michigan Technological University

Follow this and additional works at: https://digitalcommons.mtu.edu/etds

Part of the Science and Mathematics Education Commons

Copyright 2011 Deborah Corriveau

\section{Recommended Citation}

Corriveau, Deborah, "Effects of instructional changes on student learning of electrochemistry in an IB chemistry course ", Master's report, Michigan Technological University, 2011.

https://doi.org/10.37099/mtu.dc.etds/529

Follow this and additional works at: https://digitalcommons.mtu.edu/etds

8 Part of the Science and Mathematics Education Commons 


\title{
THE EFFECTS OF INSTRUCTIONAL CHANGES ON STUDENT LEARNING OF ELECTROCHEMISTRY IN AN IB CHEMISTRY COURSE
}

\author{
By \\ Deborah Corriveau \\ A REPORT \\ Submitted in partial fulfillment of the requirements for the degree of \\ MASTER OF SCIENCE \\ (Applied Science Education) \\ MICHIGAN TECHNOLOGICAL UNIVERSITY \\ 2011 \\ (C) 2011 Deborah Corriveau
}


This report, "The Effects of Instructional Changes on Student Learning of Electrochemistry in an IB Chemistry Course," is hereby approved in partial fulfillment of the requirements for the Degree of MASTER OF SCIENCE IN APPLIED SCIENCE EDUCATION.

Department of Cognitive and Learning Sciences

Signatures:

\begin{tabular}{|c|c|}
\hline Report Advisor & Shari Stockero \\
\hline Committee Member & William Yarroch \\
\hline Committee Member & Bruce Pletka \\
\hline Department Chair & Brad Baltensperger \\
\hline Date & \\
\hline
\end{tabular}




\begin{abstract}
This study investigated the effectiveness of incorporating several new instructional strategies into an International Baccalaureate (IB) chemistry course in terms of how they supported high school seniors' understanding of electrochemistry. The three new methods used were (a) providing opportunities for visualization of particle movement by student manipulation of physical models and interactive computer simulations, (b) explicitly addressing common misconceptions identified in the literature, and (c) teaching an algorithmic, step-wise approach for determining the products of an aqueous solution electrolysis. Changes in student understanding were assessed through test scores on both internally and externally administered exams over a two-year period. It was found that visualization practice and explicit misconception instruction improved student understanding, but the effect was more apparent in the short-term. The data suggested that instruction time spent on algorithm practice was insufficient to cause significant test score improvement. There was, however, a substantial increase in the percentage of the experimental group students who chose to answer an optional electrochemistry-related external exam question, indicating an increase in student confidence. Implications for future instruction are discussed.
\end{abstract}




\section{Acknowledgements}

There were many people who provided encouragement and support in the completion of this project, which provides the capstone for a master's degree in education.

First, I would like to thank my advisor at Michigan Tech, Dr. Shari Stockero. Thanks for keeping me going and always being ready to respond to questions in a timely manner, even when I appeared to ignore this project for weeks at a time.

Secondly, I would like to thank my family. Thanks to my husband, Bill, for being supportive, a willing listener and for remembering enough of what he has learned about chemistry to be ready to discuss difficulties in learning the subject. Thanks also to my children for understanding my occasional unavailability and being able to empathize with my need to do my homework.

I would also like to thank my science teaching colleagues at Notre Dame Academy; Ann Hollenbeck, Sue Nelson, Andrea Hearden and Joy Mayer. They have provided support, inspiration and a shoulder to lean upon in times of doubt. Special thanks to Sheila Gelhausen from Ronald Reagan High School in Milwaukee for sharing her favorite electrochemistry website and student worksheets.

Lastly I wish to thank my students, especially the IB senior class of 2011, who spent two years with me learning the higher-level chemistry curriculum. They were a very special group and will never be forgotten. Thank you for your curiosity, willingness to try new things and always being ready to give it your best shot. 


\section{Table of Contents}

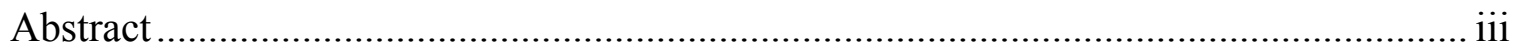

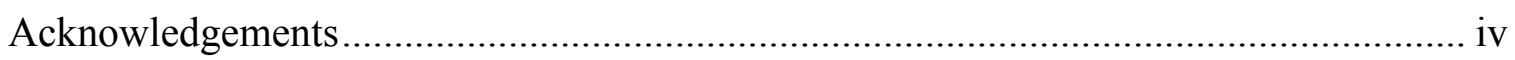

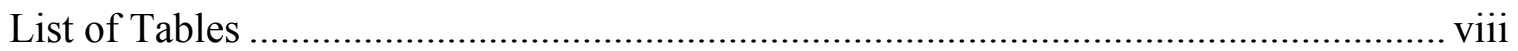

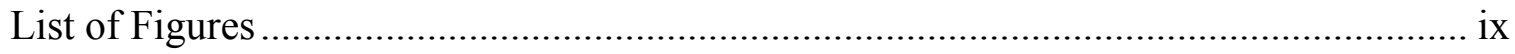

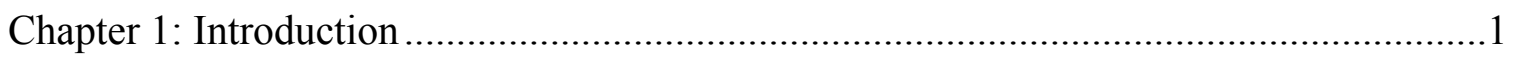

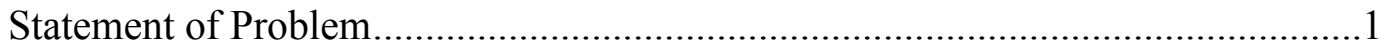

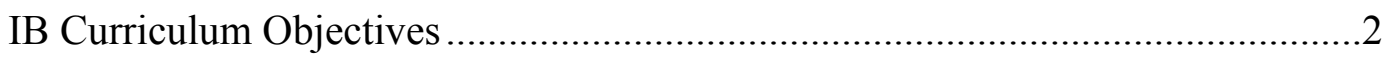

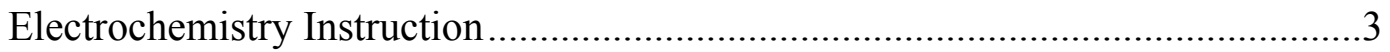

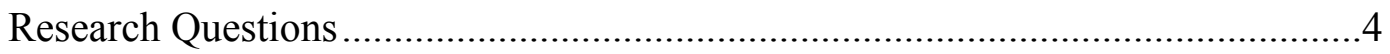

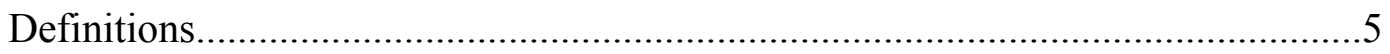

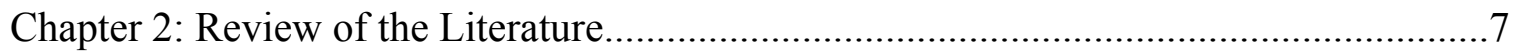

Definition of Electrochemistry ……………………...................................

Difficulties in Teaching Electrochemistry .......................................................

Understanding Electrochemistry ................................................................

Common Student Misconceptions .....................................................................10

Techniques for Teaching Electrochemistry ....................................................12

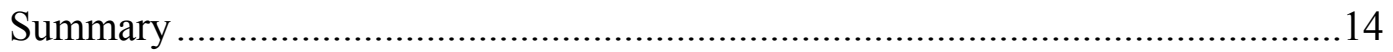

Chapter 3: Participants, Procedures and Methodology ..................................................15

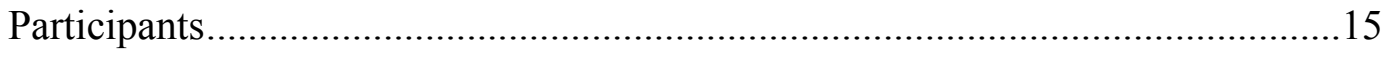

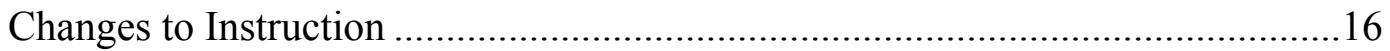

Addressing Common Misconceptions ......................................................17 
Providing Opportunities for Dynamic Visualization

Teaching an Algorithmic Approach.........................................................18

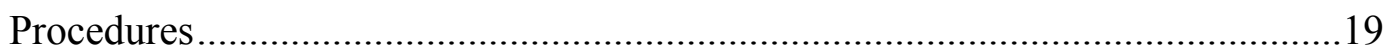

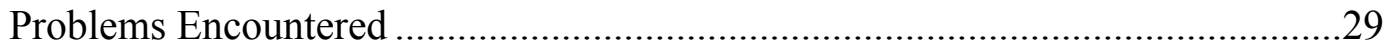

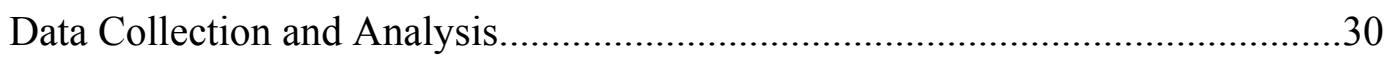

Formative Assessment of Voltaic Cells ....................................................30

Summative Assessment: Internal Exam....................................................31

Prior Year’s IB External Exam Question...................................................32

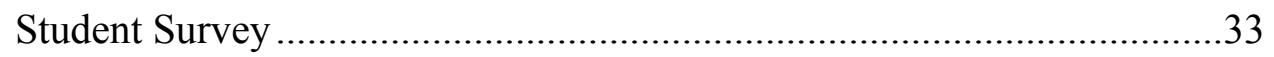

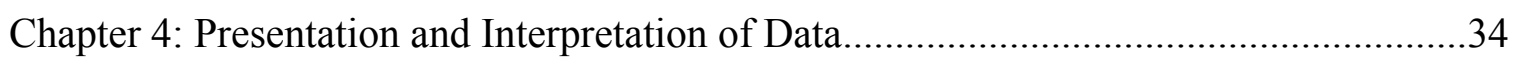

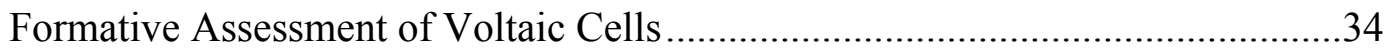

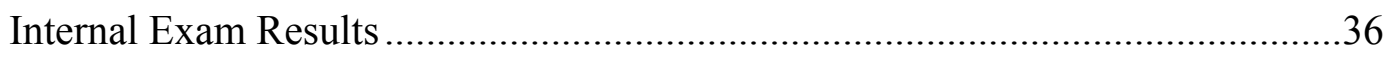

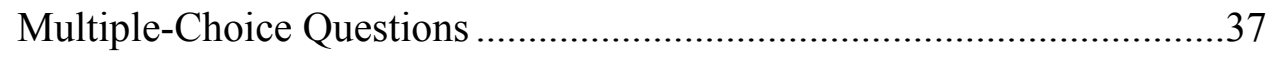

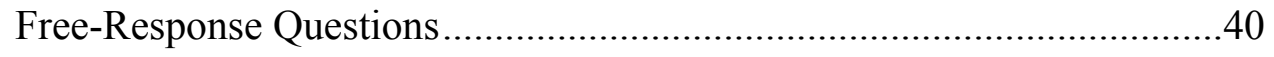

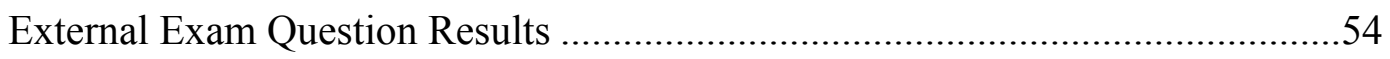

Experimental Student Survey on External Exam Questions.................................62

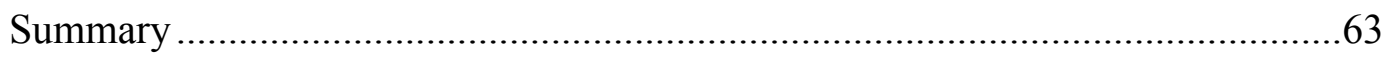

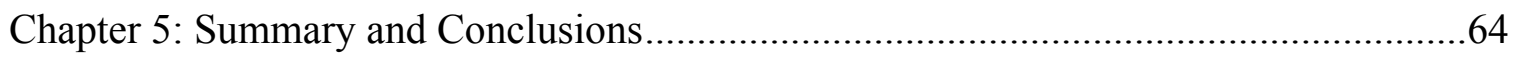

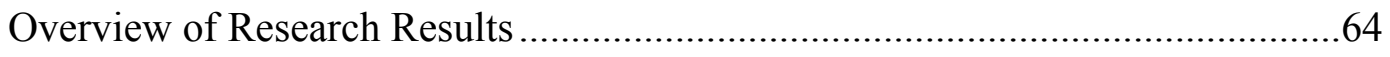

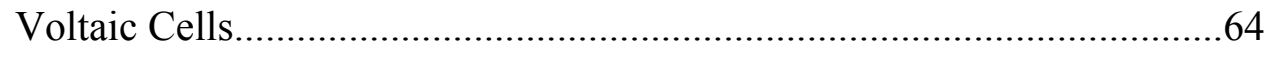

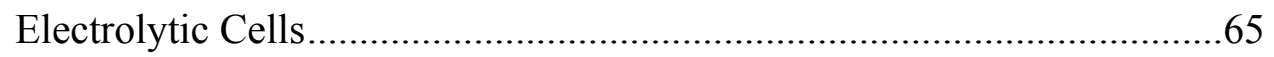

Student Attitude Toward Electrochemistry ...............................................68 
Recurring Errors and Misconceptions ............................................................6

Misconception about Electrolytic Conductivity ..........................................68

Misunderstandings about the Use of Equilibrium Arrows .........................69

Misconceptions about Calculating Cell Potential .......................................71

Misconceptions about the SHE.................................................................72

Errors in Using the Algorithm for Electrolytic Cell Products .....................74

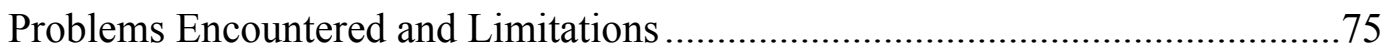

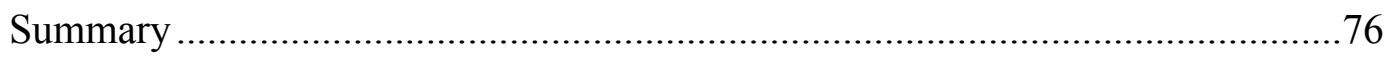

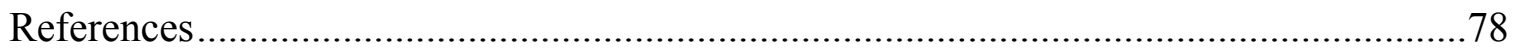

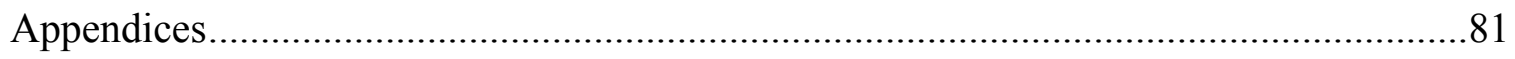

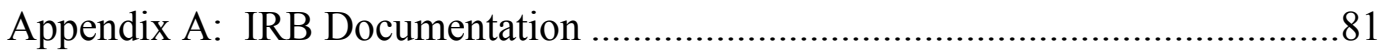

Appendix B: Common Student Misconceptions in Electrochemistry ...................84

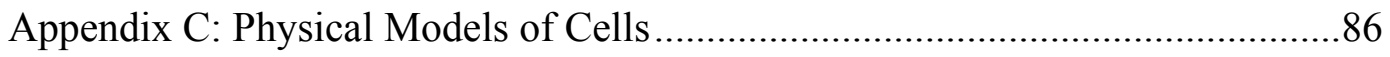

Appendix D: Interactive Lab Investigating Voltaic Cells....................................87

Appendix E: Laboratory Instructions for Building a Voltaic Cell........................90

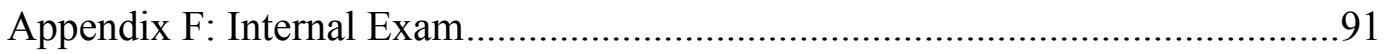

Appendix G: External Exam Question and Rubric...............................................96 


\section{List of Tables}

Table 1: Results for Multiple Choice Questions 2, 3, 5, and 6 from Internal Exam .........37

Table 2: Results for Questions 10 a-e from Internal Exam ...........................................40

Table 3: Results for Questions 4 and 11 a-g from Internal Exam .................................46

Table 4: Results for Questions 6 a-d from 2010 IB External Exam ................................55 


\section{List of Figures}

Figure 1: Internal Exam Results for Multiple Choice Questions....................................38

Figure 2: Internal Exam Results for Voltaic Cell Questions (10 a-e).............................41

Figure 3: Internal Exam Results for Electrolytic Cell Questions (4, $11 \mathrm{a}-\mathrm{g})$....................46

Figure 4: Common Student Errors when Calculating Cell Potential...............................57 


\section{Chapter 1}

\section{Introduction}

\section{Statement of Problem}

One of the most difficult units in the International Baccalaureate (IB) higher-level chemistry curriculum is that of oxidation and reduction. A particularly confusing topic within this unit is electrochemistry, including voltaic and electrolytic cells. Like much of the study of chemistry, the subject matter is abstract and the process itself is invisible to the eye, while only the effect is observable. In the voltaic cell, the spontaneous movement of charged particles results in the creation of voltage potential. This is the basic principle behind the operation of a battery. In electrolytic cells, however, an outside source of electricity is used to push desired but non-spontaneous reactions to occur. The two types of cells have some similarities but also have several differences. To comprehend these topics at the required level, both conceptual and algorithmic understanding is necessary.

Similar to the Advanced Placement program, the IB organization administers a set of external exams at the end of a two-year chemistry course to determine whether a student receives credit for the course. A score of 3 out of 7 is considered a passing score in the IB curriculum and may be sufficient for receipt of college credit at some universities. The first external exam consists of 40 questions in a multiple-choice format. Specific student responses are not available to the instructor for this part of the exam. The second external exam consists of six multi-part, free-response questions. Scored copies can be obtained by the teacher for further analysis. The first four or five multi-part 
questions of the second external exam are mandatory, whereas the student is required to answer only two of the final four, optional questions.

In analyzing the scored exam papers from the 2009-10 school year, I noted that 9 of my 16 tested, higher-level students opted to answer a multi-part, free-response question related to oxidation/reduction and electrochemistry. This was the second most popular optional question chosen by my students; however, the points earned for this question ranged from 3 to 15 out of 25 points possible. The students who chose to answer this question represented both the highest and lowest achievers in the class. Of special interest to me as an instructor was the fact that each of the three students who received failing final IB chemistry grades ( 2 out of 7 ) earned only 3 points out of 25 possible on this question. Clearly, this was an instructional area in need of improvement.

\section{IB Curriculum Objectives}

The IB Higher Level Chemistry Syllabus (International Baccalaureate Organization, 2007) includes a number of specific objectives related to voltaic and electrolytic cells. These are listed below, with higher-level objectives noted by an asterisk.

\section{$9.4 \quad$ Voltaic Cells}

9.4.1 Explain how a redox reaction is used to produce electricity in a voltaic cell.

9.4.2 State that oxidation occurs at the negative electrode (anode) and reduction occurs at the positive electrode (cathode).

19.1 Standard Electrode Potentials 
*19.1.1 Describe the standard hydrogen electrode.

*19.1.2 Define the term standard electrode potential $\left(\mathrm{E}^{\circ}\right)$.

*19.1.3 Calculate cell potentials using standard electrode potentials.

*19.1.4 Predict whether a reaction will be spontaneous using standard electrode potential values.

\subsection{Electrolytic Cells}

9.5.1 Describe, using a diagram, the essential components of an electrolytic cell.

9.5.2 State that oxidation occurs at the positive electrode (anode) and reduction occurs at the negative electrode (cathode).

9.5.3 Describe how current is conducted in an electrolytic cell.

9.5.4 Deduce the products of the electrolysis of a molten salt.

\subsection{Electrolysis}

*19.2.1 Predict and explain the products of electrolysis of aqueous solutions.

*19.2.3 Describe the use of electrolysis in electroplating.

\section{Electrochemistry Instruction}

In general, my second year chemistry students have few preconceived notions about electrochemistry, since they have had limited exposure to the topic before the IB course. If they opted to take an advanced biology course in their junior year, some of my students' may have experience with biological definitions of oxidation-reduction. A few of my students have had exposure to the topic of electricity in a second year of IB senior 
year physics. In the first year of chemistry, all of my students learn the term "electrolyte" and observe a demonstration that illustrates that an electric circuit can be completed in a $\mathrm{NaCl}$ aqueous solution but not in plain water or in a sucrose solution. In general, though, the second year of IB chemistry is where my chemistry students first encounter the topic of electrochemistry so I am not working to eliminate any specific, well-established misconceptions.

In the past, I used lecture and diagramming on a board to teach this topic with the IB objectives as an outline. In this study, a three-pronged approach was used to try to improve student understanding of electrochemistry. First, I thought a better conceptual understanding of particle flow would allow students to be able to visualize what happens in both types of electrochemical cells. I planned to accomplish this by having the students experience computer simulations and also manipulate physical, concrete models of electrochemical cells. Second, I planned to explicitly address common misconceptions about how electrochemical cells operate. The third prong of my instructional approach would be to practice, with the students, using a step-by-step process to accurately predict the products of aqueous solution electrolysis.

\section{Research Questions}

The aim of this study was to understand how the specific changes to my instruction described above would affect students' understanding of electrochemistry. In particular, the following research questions were addressed: 
(1) To what extent did visualization practice in the form of model manipulation and computer simulations improve students' conceptual understanding of voltaic and electrolytic cells?

(2) To what extent did explicit instruction that addressed commonly held misconceptions dispel or prevent misconceptions about electrochemistry?

(3) To what extent did practice using a specific algorithmic process improve students' ability to predict the correct products resulting from electrolysis?

(4) Did incorporating the above strategies into instruction result in more students either (a) achieving improved scores on the IB external exam electrochemistry test question(s)or (b) choosing to answer the electrochemistry question on the IB exam when it was given as an option?

\section{Definitions}

The following terms will used in this paper and are defined as follows:

Visualization - to form a mental image of an abstract, invisible process.

Conceptual understanding - to be able to interpret verbal or pictorial representations of scientific ideas.

Algorithmic understanding - to be able to perform step-by-step or mathematical operations to determine a solution to a scientific question.

Electrochemistry - the study of chemical reactions that produce electricity and how to use electricity to produce chemical reactions.

Electrochemical cells_-voltaic cells and electrolytic cells Voltaic cells - apparatus that combines spontaneous chemical reactions to produce 
electricity.

Electrolytic cells - apparatus that uses an outside source of electricity to cause nonspontaneous chemical reactions to occur.

Electrolysis - the process that occurs in an electrolytic cell. 


\section{Chapter 2}

\section{Review of the Literature}

\section{Definition of Electrochemistry}

Electrochemistry is a process in which electricity and chemical reactions work together to create a desired outcome. In voltaic cells, spontaneous oxidation-reduction reactions are utilized to create electricity. This is the working principle behind a battery. In electrolytic cells, electricity introduced from an outside source is used to push nonspontaneous, but desired, chemical reactions to occur. For example, electrolysis is used to produce pure sodium metal and chlorine gas from common table salt. Electrolysis is also the principle employed in electroplating, a process that is used to cover a cheaper metal part with a second metal that is more resistant to corrosion, such as chromium. Electrochemical cells of both types involve movement of electrons and ions.

\section{Difficulties in Teaching Electrochemistry}

In a survey of Wisconsin high school chemistry teachers (Finley, Stewart, \& Yarroch, 1982), topics were rated by difficulty and the top three, respectively, were chemical equilibrium, the mole, and oxidation-reduction reactions. It is not surprising, then, that electrochemistry is a difficult subject for both teachers and students, since an understanding of all three of these topics is needed to adequately understand electrochemical phenomena. Similar results have been found in other countries. In a survey of Australian high school chemistry students, the most difficult topic to understand was "the connection between cell voltage and the relative strength of the 
oxidant and reductant” (Butts \& Smith, 1987, p.49). One of the reasons electrochemistry is an especially difficult subject to teach is because the particles and their movement cannot be seen with the eye (Ozkaya, Uce, Saricayir, \& Sahin, 2006). For example, ions and electrons are invisible to the eye and thus teaching about them requires a teacher to be creative.

\section{Understanding Electrochemistry}

An in-depth understanding of electrochemistry requires both conceptual and algorithmic knowledge. High schools in the U.S. tend to emphasize and assess the algorithmic, quantitative, problem solving of electrochemistry, neglecting conceptual understanding (Sanger \& Greenbowe, 1997a). Unfortunately, research has shown that algorithmic understanding of a topic does not necessarily translate into conceptual understanding in chemistry (Nakhleh, 1993). In research done regarding student difficulties with electrochemistry, Niaz (2002) reports that "the ability to solve routine problems based on memorized formulae does not transfer readily to problems that require conceptual understanding” (p.435). Researchers Ceyhun and Karagolge (2005) also report that students who held misconceptions regarding electrochemical concepts were still able to calculate cell potentials correctly. Ozkaya (2002) attributes learning difficulties in electrochemistry to a general lack of conceptual understanding and attributes this to insufficient textbook explanations of these concepts. A small variation in the complexity of questions about electrochemistry "increases the degree to which the problem requires conceptual understanding" (Niaz, 2002, p.435). 
When teachers focus on teaching and assessing the particulate nature of the electrochemical processes, conceptual knowledge is improved (Sanger \& Greenbowe, 1997a), thereby improving students' overall understanding of electrochemistry. So how can a teacher best build student understanding of the particulate nature of electrochemical processes? One possibility is the use of visual aids.

Dual coding theory states that learned information can be coded into the working memory verbally or pictorially. If a visual aid is available, it allows a concept to be encoded into memory as both words and pictures. The theory contends that this is the optimal situation because if verbal memory is lost, the pictorial representation will still be available (Sanger \& Greenbowe, 2000, p.522).

The dual coding theory originally referred to the use of static visual aids but Park and Hopkins (1993) report that "dynamic visual displays are more effective than static ones." In fact, several researchers report success with dispelling student misconceptions utilizing computer animations showing particle movement in voltaic and electrolytic cells (e.g., Acar \& Tarhana, 2006; Sanger \& Greenbowe, 1997b). Furthermore, Sanger and Greenbowe (2000) suggest "that novice learners... should be prompted to watch for relevant details" (p. 522) to maximize their learning experience while using computer animation.

When studying the mole and kinetic molecular theory, Howe and Durr (1982), found that the interactive use of concrete, manipulable materials, combined with peer interaction, improved students' conceptual understanding whether they were operating at the concrete or the formal operational levels. The interactive use of models allows for "real objects, situations and experiences to form the basis for logical thinking" (p.225), while "structured peer interaction induces cognitive conflict that will in turn lead to 
learning" (p.225). Huddle, White, and Rogers (2000) add that students appeared to gain more from a hands-on manipulation of a concrete model of an electrochemical cell than they derived from observing a teacher-led demonstration of the same model.

\section{Common Student Misconceptions}

Another issue with learning electrochemistry is an abundance of student-held misconceptions about this topic. Over the past twenty years, much research has been done on commonly held misconceptions in the area of electrochemistry. Reasons for the misconceptions are varied, including textbook authors and teachers who are guilty of making inadvertent simplifications or using vague and misleading terminology (Acar \& Tartan, 2006; Sanger \& Greenbowe, 1999).

An example of a simplification would be repeatedly illustrating a voltaic cell with the anode on the left side, inferring that the relative location of the electrode determines the nature of the particular oxidation (or reduction) reaction that occurs there (Sanger \& Greenbowe, 1999). Terms with multiple meanings add to students' general confusion. For example, electrolysis can be interpreted as chemically breaking apart by means of electricity, yet this definition does not necessarily correctly explain the purpose or action of an electrolytic cell (Schmidt, Marohn, \& Harrison, 2007). The purpose of an electrolytic cell is not to break up a substance into ions, but to take existing ions out of a molten salt (or a solution) and form elemental substances from them via oxidation or reduction. Also, students may incorrectly reapply a term learned in another context, such as asserting that the cathode electrode should always be represented by a negative charge 
because they had previously learned in physics that a cathode ray was made up of negatively charged electrons.

Another issue is that textbooks often make inappropriate analogies, such as comparing the electrochemical cell to the water cycle in which a single particle, a water molecule, moves in one direction, completing the entire cycle (Schmidt, Marohn, \& Harrison, 2007). This leads students to incorrectly infer that a single particle, for example, an electron, will follow a complete cycle in one direction through a voltaic or electrolytic cell. Another issue that adds to the difficulty of understanding electrochemistry is the relative nature of electrochemical cell potentials (Sanger \& Greenbowe, 1997a). Like several other chemistry topics, including enthalpy and free energy, chemists cannot make absolute potential measurements of a single oxidation (or reduction) reaction but must compare each half reaction to a mutually agreed upon standard, the standard hydrogen electrode. Only in comparison to this seemingly arbitrary standard can cell potential be quantified.

Another common misconception pertains to the convention of using charge symbols (i.e., + and -) to designate the anode and cathode in electrochemical cell drawings. The electrodes actually carry extremely small net charges. In a voltaic cell, the designated positive or negative signs symbolize the relative tendency to be oxidized or reduced, and thus are used to identify the anode or the cathode. But, in lieu of a thorough conceptual understanding, students will attempt to use previously acquired general knowledge, such as attempting to use the designated electrode charges and electrostatic 
arguments, to (incorrectly) explain how and why the various charged particles flow in particular directions in an electrochemical cell (Ozkaya et al., 2006).

\section{Techniques for Teaching Electrochemistry}

Various teaching techniques have been used to successfully teach electrochemistry and to correct common misconceptions. Thompson and Soyibo (2002) report that the addition of student practical work to the usual combination of lecture, teacher demonstrations and class discussion improved students' test scores and attitudes toward chemistry. Niaz (2002) used a carefully orchestrated set of algorithmic questions to "generate situations/experiences in which small groups of students are forced to grapple with alternative responses leading to cognitive conflicts/contradictions" (p.430). The results of this approach were significantly better post-test scores for the experimental group, leading the researcher to conclude that the students' conceptual understanding of electrochemistry had surpassed that which was needed for routine algorithmic problemsolving.

Ozkaya and colleagues (2006) used "conceptual change texts that evoke learners' preconceptions, caution learners about common misconceptions and contrast the misconceptions with scientifically accepted conceptions by using examples and explanations" (p.1719). These conceptual change texts were immediately followed by two tier assertion-reason style questions to better assess learning and uncover misconceptions. Improved post-test scores were noted on both conceptual and algorithmic test questions, which the researchers attributed to improved understanding of how electrochemistry concepts are related and an ability to "organize relevant concepts in 
related categories" (p.1721). These researchers and others (e.g., Ogude \& Bradley, 1994) advocate explicitly informing students about common misconceptions during the course of instruction.

There are also several options available to teachers to help students visualize abstract electrochemistry concepts. Analogies can be made to macroscopic phenomena. For example, the attraction of a positively charged particle and a negatively charged particle can be compared to the attraction between opposite poles of a magnet (e.g., Brown, LeMay, \& Bursten, 2006). Visible effects resulting from submicroscopic particle interactions can be demonstrated, as in the case of new and different-looking products formed in a chemical reaction. But often, a chemistry teacher must resort to concrete models, for example ball and stick models, to help visualize molecular shapes (e.g., Brown, LeMay, \& Bursten, 2006). More recently, computer animation has been added to the chemistry teacher's toolbox.

Acar and Tarhan (2006) report success with using student cooperative learning groups and computer animations. Other researchers also report improved understanding with the use of computer simulations (Ceyhun \& Karagolge, 2005; Sanger \& Greenbowe, 1997b). In a case where computer access was lacking, South African teachers have used physical models made of wooden compartments containing Styrofoam balls and marbles representing atomic and subatomic particles (Huddle, White, \& Rogers, 2000). In this case, it was found that the "[U]se of the model led to significant improvement in students' understanding of what was occurring at the microscopic level in an electrochemical cell and helped to address known alternate conceptions" (p.109). 


\section{Summary}

In summary, electrochemistry is a difficult topic for students to master.

Traditionally, in the U.S. education system, algorithmic problem solving has been stressed but this is insufficient when questions are non-routine. In-depth understanding requires both algorithmic and conceptual knowledge of invisible particles and their movements. Conceptual knowledge does not necessarily follow from algorithmic understanding. Concrete model manipulation and studying computer animations of microscopic particle movement appears to improve students' conceptual understanding of voltaic cells. Researchers also recommend explicitly addressing common misconceptions prevalent in the subject of electrochemistry to dispel misunderstandings and clarify the principles at work. 


\section{Chapter 3}

\section{Participants, Procedures and Methodology}

The stance taken in this research was that (a) improving conceptual knowledge of electrochemical processes by providing opportunities for visualization of particle movement, (b) explicitly addressing common misconceptions, and (c) teaching students an algorithmic, step-wise approach for determining the products of an aqueous solution electrolysis would improve student understanding of electrochemistry. These changes made to the way that the electrochemistry portion of the unit was previously taught were intended to specifically address several of the IB standard and higher level learning objectives (see Chapter 1). Changes in student understanding were assessed through test scores on both internally and externally administered exams.

\section{Participants}

There were 13 students in the experimental group when the study took place, all of whom were high school seniors. These students were all enrolled in an IB chemistry course that was taught by the instructor/researcher. Eleven of the thirteen were concurrently enrolled in IB higher-level math or college credit calculus classes. On a cumulative semester examination taken just prior to electrochemistry instruction, the class average score was 41 out of 50 points (83\%) with a standard deviation of 4.1 points. The students were predominantly Caucasian and were evenly split in gender, with six females and seven males. Two of these students, one male and one female, did not intend to complete the IB administered external examination that was to take place in May 2011. Before the unit began, the students were informed of the instructor's intent to use their 
work in this study and that if they agreed to participate in the study, their specific results would remain anonymous. Written consent was obtained from the students and their guardians (see Appendix A for IRB documents).

The comparison group consisted of students who were enrolled in the IB chemistry course during the previous school year, and was made up of 18 high school seniors. Twelve of the eighteen were concurrently enrolled in IB higher-level math, while the rest were taking the less advanced IB math studies course. On a cumulative semester examination taken just prior to electrochemistry instruction, the average class score was 39 out of 50 points $(79 \%)$ with a standard deviation of 6.2 points. The students were predominantly Caucasian and evenly split between the genders, with eight females and ten males. One female did not complete the external exam due to illness and one male opted to take the less rigorous standard-level IB external exam, providing a comparison data sample size of sixteen for the external exam. For both groups, the sample size was admittedly small; however, these were the only test subjects available to the researcher.

\section{Changes to Instruction}

Three major modifications to instruction were made during the study: (a) explicitly addressing common misconceptions, (b) providing opportunities for dynamic visualization of particle movement, and (c) teaching students an algorithmic, step-wise approach for determining the products of an aqueous solution electrolysis. The goal was to improve student understanding of electrochemistry. Each modification is described in the following. 


\section{Addressing Common Misconceptions}

Explicitly addressing common misconceptions was done during lecture at the time that a particular concept was first introduced. A summary list of common misconceptions that were addressed is found in Appendix B. As an example, when discussing the directional movement of ions in a salt bridge toward a particular half-cell of a voltaic cell, the need to maintain electrical (charge) neutrality in each half-cell was stressed. Students were then asked whether a conducting copper wire could replace a salt bridge between half-cells. The students concluded, with some guidance, that since the wire is unable to supply the charged particles to the electrolyte solution that are needed to maintain electrical neutrality, a copper wire could not perform the same function as a salt bridge.

\section{Providing Opportunities for Dynamic Visualization}

Physical model manipulation and computer simulation exercises were intended to improve general conceptual understanding by providing dynamic visualization and clarification of particle movement. The use of these models addressed all of the previously listed objectives under voltaic and electrolytic cells, except for Objective 19.2.1: Predict and explain the products of electrolysis of an aqueous solution.

To construct six electrochemical cell models, about \$200 worth of Styrofoam balls, plastic hose, marbles, paint, screws and other hardware was purchased. Using wooden planks that had been previously cut for chemical storage boxes, these models were constructed prior to the start of the unit. The original design suggested by Huddle and White (2000) was modified so the models would lay flat on a lab bench and could be 
used as either a voltaic or electrolytic cell model. The main modification consisted of adding a bottom-hinge on a vertical wooden flap divider so that, when up, it could represent a semi-permeable membrane/salt bridge for a voltaic cell. When the divider was down, this same model could be used to represent the single electrolyte chamber of an electrolytic cell (Appendix C).

Upon the recommendation of another IB chemistry teacher in Wisconsin, a computer simulation website (Demonstration of a Voltaic Cell, n.d.) was identified that would sufficiently illustrate particle movement within a voltaic cell and also allow students to manipulate variables on a controlled basis to observe how voltage was affected. This teacher also shared a copy of a written worksheet (Appendix D) that she had used with her students, which was also used during the unit. The computer simulation and associated worksheet were completed in student pairs in the computer lab of the school. This learning process was intended to be repeated with the electrolytic cell but a similar, suitable website showing molten salt electrolysis could not be found. Instead, a simulation of an electrolytic cell for purification of copper with an aqueous electrolyte (Electrolytic Cell, n.d.) and an online demonstration of electroplating (Chromium Plating Metal, n.d.) were identified for use.

\section{Teaching an Algorithmic Approach}

Introducing an aqueous solution into an electrolytic cell creates a situation in which several products are possible. Because students have difficulty figuring out the resulting products, the remaining objective (19.2.1: Predict and explain the products of electrolysis of an aqueous solution) was addressed by introducing an algorithmic, step- 
wise method for identifying the various products possible and correctly determining which products would be made at each electrode.

During instruction, the instructor practiced with the students identifying which substances would be preferentially reduced or oxidized in an electrolytic cell containing an aqueous solution electrolyte. This included discussing the possibility of water being oxidized or reduced in the decision-making process and that the outcome is based upon the relative positions of the half-reactions for the oxidation or reduction of water versus the other available atoms/ions on the standard reduction potentials table. The difference between the instruction in the study and that of previous classes was the teaching of a very deliberate, methodical decision-making process. All substances capable of undergoing oxidation were listed and students chose the substance that was located nearest the top right side of the reduction potential table as the one most easily oxidized. Then all possible candidates for reduction were listed and students chose the substance located nearest the bottom left of the reduction potential table as the one most easily reduced. Thus the available species (ion or atom) which is the most easily oxidized substance will yield one product at the anode, while the species most easily reduced will yield another product at the cathode.

\section{Procedures}

The electrochemistry unit was taught following an introduction to oxidation/reduction in the second year of a two-year course, International Baccalaureate Chemistry-Higher Level. The general consensus among previous years' students had been that this was one of the most difficult chapters in the curriculum. This chapter was 
taught in February over the course of four weeks, with two weeks of electrochemistry being taught immediately following a two-week introduction to oxidation and reduction, balancing chemical reactions using the half-reaction method, and reactivity series. The researcher was the teacher for the unit.

The goal of the changes made in teaching methods for electrochemistry was to improve conceptual understanding of the sub-microscopic particle flows in a voltaic and electrolytic cell, which was expected to improve test scores on both internal and external assessments. The specific learning activities used to accomplish this goal are described below.

\section{Day One}

The instruction during day one was altered to include addressing common misconceptions. The teacher introduced voltaic cells in lecture by explaining their purpose, drawing a zinc/copper cell on the board, annotating each part in the drawing and diagramming particle flows. Students had notes in front of them and also annotated their own diagram of the same cell. The teacher stated that the relative location of each electrode (left-side or right-side) in the drawing did not dictate the identity of the anode vs. the cathode, but rather, the different metals' relative willingness to be oxidized. Very little emphasis was placed on the relative charges of the anode vs. the cathode electrodes, as it is believed that this often leads to misconceptions and confusion regarding the direction of particle movement (Ogude \& Bradley, 1996; Schmidt, Marohn, \& Harrison, 2007). To prevent some common misconceptions, the teacher reiterated that electricity flows through an electrolyte solution without the presence of delocalized electrons and 
stressed the need to maintain electrical (charge) neutrality using electrolyte ion movement from the salt bridge into each half-cell electrolyte solution.

During the last ten minutes of the class student pairs went into the lab and, following verbal instructions, manipulated physical models of zinc/copper voltaic cells by:

(a) removing a silver-colored, Styrofoam ball representing a zinc atom from the oxidized anode electrode compartment;

(b) removing the two marbles embedded in the Styrofoam ball, representing two electrons, and placing those freed marbles into a plastic hose at the top of the model which connects the anode to the cathode electrode;

(c) placing the remaining zinc ion (silver-colored, Styrofoam ball minus two marbles) into the electrolyte "solution" compartment of the anode side halfcell;

(d) removing two marbles from the plastic hose nearest the copper cathode;

(e) removing a copper-colored, Styrofoam ball with open spots for two marbles, representing a copper ion in solution, from the electrolyte compartment of the cathode side half-cell and embedding two marbles in the Styrofoam ball before adding it to the copper atoms already in the cathode compartment;

(f) discussing the need for electric neutrality in each half-cell solution and counting number of positive and negative ions in each half-cell compartment then deciding whether to move Styrofoam balls representing cations or anions, 
and how many of each needed to move across the half-cell divider to achieve electrical neutrality in each half-cell electrolyte solution; and

(g) noting which electrode had increased in mass and which had decreased, as well as what had happened to the concentration of each metal cation in each half-cell's electrolyte solution.

\section{Day Two}

Because of an unexpected three-day weekend due to snowfall, the planned voltaic cell computer simulation activity had to be postponed. Class began with review of a voltaic cell diagram. Again, instruction was modified from that in previous years to address common student misconceptions. The standard reduction potential table was introduced and the method for calculating a cell's voltage potential was introduced as

$$
\mathrm{E}^{\circ} \text { cathode }-\mathrm{E}^{\circ} \text { anode }=\mathrm{E}^{\circ} \text { cell }
$$

An analogy was made to Hess' Law and, in particular, the ability to reverse a reaction and simply reverse the sign of the associated heat value. This explains the need to subtract the $\mathrm{E}^{\circ}$ anode value, since conventionally all standard reduction potential tables are shown as reductions and the reverse reaction of oxidation occurs at the anode. However, it was emphasized that while heat is an extensive property, voltage potential is intensive. Therefore, reduction potentials are never multiplied by a factor when more moles of reactant react. The difference in voltage potential between two half-cells was compared to the potential energy present due to the height of a waterfall. The height of the waterfall is unaffected by the amount of water falling, which would represent more 
electrons (current) flowing. Finally, it was discussed that a positive E cell value indicates a spontaneous reaction.

The relative nature of the standard reduction potentials table and the impossibility of measuring the voltage of a single half-cell were stressed. The standard hydrogen electrode was presented as the half-cell arbitrarily chosen for comparison purposes and against which all other half-cells voltage potentials are measured. The location of the hydrogen reduction half-reaction and its assigned value of zero volts in the center of the standard reduction table were noted. It was explained that reduction reactants above the hydrogen reduction half-reaction represented substances that were less easily reduced, while those below the hydrogen reduction half-reaction were more easily reduced.

\section{Day Three}

The day three instruction was the same as in previous years. Students were sent into the chemistry lab with a basic set of directions for constructing a voltaic cell using an inner porous cup (in lieu of a salt bridge) and outer plastic cup assembly, voltmeter, and wires with alligator clips (Appendix E). Electrode strips of various metals and their associated 1M solutions containing each metal's ions were available. Students recorded the actual voltage output and compared their lab value to theoretical voltages that they calculated using the standard reduction potential table.

\section{Day Four}

As had been done in previous years, students were given class time to design an experiment in which they tested whether and how a particular variable (of their choice) 
would affect the voltage output of a voltaic cell. They were asked to carefully consider controls and explain how those controls would be maintained.

\section{Day Five}

During day five, computer simulations that were originally scheduled for day three were completed. Students paired up in the computer lab to observe and manipulate a voltaic cell simulation (Demonstration of a Voltaic Cell, n.d.). The teacher began by explaining that in the $\mathrm{Ag} / \mathrm{Cu}$ voltaic cell animation, a silver ion only required one electron to be reduced while each $\mathrm{Cu}$ atom gave up two electrons. Because of this, for the same electron flow, twice as many silver atoms could be reduced as copper atoms oxidized. This was different than the classic $\mathrm{Cu} / \mathrm{Zn}$ voltaic cell that had been introduced in the lecture, where for every two electrons exchanged, one copper atom was reduced and one zinc atom was oxidized. Students then proceeded to complete a worksheet (Appendix D) while manipulating the simulated voltaic cell with various combinations of electrode/electrolyte in each half-cell; the worksheet required them to diagram particle flow and record voltage output.

\section{Day Six}

As a class, students took turns verbally answering and filling in the answers to questions from a test bank of old IB external exam questions on the topics of voltaic cells, standard hydrogen electrode and calculating voltaic cell potentials. This was an activity that was also completed in previous years. 


\section{Day Seven}

A short, formative assessment of voltaic cell understanding was administered and collected (DiStasio, 1995). This activity was added to the instruction to informally check student understanding of voltaic cells following physical model manipulation and computer simulation exercises. This was completed to check for misconceptions before beginning lecture on the subject of electrolytic cells. The voltaic cell assessment checked for ability to identify anode vs. cathode, calculate a cell potential voltage, and determine direction of particle flows and changes in electrodes and electrolyte solutions over time. It was informally corrected and passed back to students; a general discussion of errors took place in class the following day.

Following the assessment, electrolytic cells with inert electrodes and a $\mathrm{NaCl}$ molten salt electrolyte were introduced in lecture as was done in previous years. Instruction during day seven was altered, however, to include addressing common misconceptions (Appendix B). The differences between voltaic cells and electrolytic cells were emphasized, especially the different purpose of an electrolytic cell, which helps to explain many of the differences in the two types of cells. Since a molten salt electrolytic cell's purpose is to produce elemental substances from the molten ionic compound, the electrodes themselves are not necessarily oxidized or reduced. Also, there is no need for two half-cells containing two different electrolyte solutions separated by a salt bridge, but a single molten salt electrolyte chamber suffices to complete the electric circuit.

Additionally, a battery is needed to drive the non-spontaneous reduction of the metal cation and oxidation of the nonmetal anion in the molten salt. The relative arrangement of 
the positive and negative terminals of the battery driving the non-spontaneous reaction determines which electrode is identified as the anode and which the cathode. A calculated cell potential for an electrolytic cell should be negative because it represents a nonspontaneous, oxidation/reduction reaction.

\section{Day Eight}

Lecture began with a review of similarities between voltaic and electrolytic cells, including:

(a) Oxidation always occurs at the anode and reduction always occurs at the cathode.

(b) In the electrolyte, cations move toward the cathode electrode and anions move toward the anode.

(c) Electrical (charge) neutrality is maintained in the electrolyte solution(s).

(d) Electrical conductivity in the electrolyte is maintained by movement of ions and externally by delocalized electrons in a wire.

Then a list of differences between the two types of cells was constructed:

(a) A voltaic cell is a spontaneous, oxidation-reduction reaction that supplies electricity. Cell potential is a positive voltage.

(b) An electrolytic cell is a non-spontaneous, oxidation-reduction reaction driven by an outside source of electricity, a battery. Cell potential will be a negative voltage.

(c) Anode electrode is assigned a (-) sign in a voltaic cell but is $(+)$ in an electrolytic cell. 
(d) Cathode electrode is assigned a (+) sign in a voltaic cell but is (-) in an electrolytic cell.

(e) There are two half-cells and a salt bridge in a voltaic cell but only a single electrolyte chamber in an electrolytic cell.

(f) In an electrolytic cell, the battery terminal arrangement determines the location of the anode and cathode electrodes.

(g) In voltaic cells, the anode is the most easily oxidized electrode material. The cathode is the most easily reduced material.

(h) In voltaic cells, the electrodes themselves take part in the reactions. In a molten salt electrolytic cell with inert electrodes, only the electrolyte takes part in the reactions.

Following the last point in the list, the teacher explained that there are other possible types of and uses for electrolytic cells. An instance of this is that electrolytic cells containing non-inert electrodes can be used to purify copper. For example, a cell with two copper electrodes immersed in a copper II sulfate solution will cause the impure metal of the anode to dissolve, pushing the resulting $(+)$ copper ion through the electrolyte solution until the ion reduces out onto the cathode electrode as pure, solid copper metal. Electrolytic cells can also be used to electroplate metals. For example, the cathode might consist of an iron fork, which one wishes to plate with a thin layer of silver. The anode would consist of silver metal, which is oxidized and travels through a silver ion solution to be reduced onto the surface of the iron fork cathode. This process is 
often used to coat a cheaper metal part with a nicer-looking or more corrosion resistant material.

Finally, the idea of the electrolysis of acidified water was introduced. Using the standard reduction potentials table, the reactions showing the reduction of water to produce hydrogen gas at the cathode and the oxidation of water to produce oxygen gas at the anode were highlighted. The purpose of the acid in the water was to insure sufficient ions present for conductivity. In many aqueous ionic solutions, then, there is more than one possible substance that can be reduced or oxidized. As described previously, an algorithmic process was introduced where all possible candidates for oxidationelectrode materials, electrolyte anions and water — are listed and the substance located nearest the top right of the standard reduction table is chosen as the one most easily oxidized. (It was noted that nitrates and sulfates anions cannot be oxidized since the nitrogen and sulfur in these polyatomics are already in their highest oxidized states of +5 and +6 , respectively.) Likewise, all substances capable of being reduced are listed; generally, these are metal cations and water. The substance located nearest the bottom left of the standard reduction table, very often a metal ion, is preferentially reduced. Thus, it is possible to use the standard reduction potentials table and an algorithm to determine the specific product yielded at each of the electrodes, the anode and the cathode.

\section{Day Nine}

The internal exam (Appendix F) was administered. This was the same summative test taken by the previous year's students. The tests were graded over the weekend and major problem areas noted were balancing with half-reactions and electrolysis. The 
teacher decided to spend an additional partial class day reviewing and working hands-on with electrolysis.

\section{Day Ten}

In the first twenty minutes of class, using a lab kit from Flinn Scientific (2007), students connected 9-volt batteries to inert, graphite pencil leads. After working as a class to predict what product would be made at each electrode, the leads were placed into three different aqueous solutions of silver nitrate, copper II sulfate and zinc nitrate. A bromothymol blue indicator turned yellow in the presence of $\mathrm{H}^{+}$ions when the predicted oxygen gas was produced from the oxidation of water at the anode. If the indicator had turned green around the cathode, it would have indicated the reduction of water to produce hydrogen gas and $\mathrm{OH}^{-}$ions, but since all three metal ions, $\mathrm{Ag}^{+}, \mathrm{Cu}^{2+}$ and $\mathrm{Zn}^{2+}$, were more easily reduced than water, different colors of metals coated the graphite leads at the cathode. The teacher then demonstrated the particle movement in the electrolytic purification of copper using the same physical model that the students had previously used to simulate voltaic cells. No student manipulation of the physical model and computer simulation exercise was completed for the electrolytic cell as was done following voltaic cell instruction.

\section{Problems Encountered}

It is important to note that the voltaic cell portion of the instruction plan was completed as per the original design intent but not the electrolytic cell portion. In addition to the three planned schedule interruptions that took place during this unit of study in February 2011, there were seven unexpected schedule changes including a snow day, a 
Packer Superbowl celebration day, a lockdown security drill, two student retreats and two school musical performances attended by large subsets of the 13 students. Sometimes the unexpected interruptions just caused a change in the planned order of events. For example, the snow day occurred on the day that the school computer lab was reserved to complete the voltaic cell computer simulation and the instructor was unable to reschedule that facility until several days later. Other times, the interruptions simply caused the instructor to backtrack and review more than is usually done at the beginning of each class. There is tremendous, self-induced pressure to complete the prescribed 240 hour IB curriculum in time for the external exam in May and the instructor could not justify taking any more time to complete this particular unit knowing that if she held firmly to the original plan, it would result in not covering other material that would be included on the IB external exam.

\section{Data Collection and Analysis}

The effectiveness of the teaching methods was measured using the following instruments: (a) a formative assessment given following the voltaic cell model manipulation and computer simulation exercise; (b) a summative assessment in the form of an internal exam that was also given to students in the comparison; (c) a multi-part, free-response electrochemistry question from last year's IB external exam; and (d) a student survey. These are described in the following sections.

\section{Formative Assessment of Voltaic Cells}

A formative assessment (DiStasio, 1995) was administered to the experimental group of students following the physical model manipulation and computer simulation 
exercises for voltaic cells. A similar assessment was not completed for electrolytic cells due to time constraints. This assessment was very straightforward and taken from an existing resource book. It contained 14 short answer questions, 11 of which only had two possible answers, so could be guessed correctly $50 \%$ of the time. On the assessment, students needed to decide which electrode material acted as the anode and the cathode, identify which sub-microscopic particles flow and in what direction through the apparatus, and describe the outcomes of this movement.

The assessments were checked by the teacher to insure a basic student understanding of voltaic cells and associated terminology. Patterns in student misunderstandings were noted by the teacher and marked copies were returned to students to help them clarify misconceptions prior to proceeding further into the topic of

electrolytic cells. These formative assessments were not scored formally but were used to check for the existence of any misconceptions that might be addressed during subsequent instruction.

\section{Summative Assessment: Internal Exam}

At the end of the unit, the same internal exam (Appendix F) that was used during the previous year was administered and the results were compared between the two groups of students. The test consisted of multiple-choice and free-response questions from previous IB exams. There were no changes made to the questions on this test over the two consecutive years. However, since students are not allowed to keep their tests, there was little chance that the experimental students were familiar with either the test or 
the questions. The questions had been randomly chosen from previous IB external exams to be included in the internal exam.

In analyzing the internal exam results, only those questions related to electrochemistry - either voltaic cells or electrolytic cells — were examined. This included seven questions, two with multiple parts. These questions were analyzed for evidence of misconceptions and the percent of students who answered each question correctly was compared to determine whether the experimental students in the study demonstrated a better understanding of electrochemistry than their peers from the previous class.

\section{Prior Year's IB External Exam Question}

During a twenty minute class period (special schedule) approximately one week before the scheduled IB external exam, the experimental group was asked to complete a multi-part, free-response question on the topic of electrochemistry from the previous year's IB exam (Appendix G). This was done in a way to simulate as closely as possible the timing and testing situation for the nine students who had chosen to answer the electrochemistry question on the previous year's external exam. No special review or study of electrochemistry was undertaken beyond the normal review activities completed by individual students preparing for the pending IB external exam. In order to simulate the circumstances of the previous year, the students were not told about this informal assessment ahead of time and so did not have an opportunity to review the specific topic.

Responses to the questions were analyzed to compare student understanding before and after the changes made in instruction methods. The external exam question was in four parts and each part was graded following the IB organization's rubric. This 
assessment was not formally included as part of students' course grades, however. The average points for each part of the question earned by the experimental group students was compared to the average points earned by those in the comparison group. In addition, specific attention was given to evidence of misconceptions about free electrons conducting electrical current in an electrolyte solution that were evident among the comparison group students.

\section{Student Survey}

On Monday, May 9, 2011, 11 of the 13 students in the study completed the external IB exam; nine completed the higher-level exam and two the standard level exam. Similar to the previous year, the higher-level test included an optional free-response question targeting electrochemistry knowledge. On Wednesday, May 11, 2011, the teacher surveyed the students to find out how many chose to answer the optional, freeresponse question on the topic of electrochemistry. The percent of students who reported answering the question was compared to the percent of students who answered the question in the previous year as a measure of student confidence about the understanding of electrochemistry topics. 


\section{Chapter 4}

\section{Presentation and Interpretation of Data}

To answer the research questions, four sources of data were analyzed. First, a formative assessment, completed only by the experimental group following physical model manipulation and computer simulations of voltaic cells, was informally analyzed for understanding and misconceptions. Secondly, an analysis was done on the results of the internal exam that was given immediately following instruction on the topic of oxidation/reduction and electrochemistry. The experimental groups' results were compared to those of the comparison group who did not experience the changes in instruction described previously. During the analysis, special attention was given to evidence of misconceptions. A third analysis was completed of both comparison and experimental student answers to the previous year's IB external exam free-response question on electrochemistry. The timing of this assessment was in early May for each group. Finally, a survey of experimental students was conducted following the IB external exam to determine how many chose to answer the optional electrochemistry free-response question. The data and the results of each analysis are discussed in the following sections.

\section{Formative Assessment of Voltaic Cells}

The formative assessment on voltaic cells was administered during class, graded informally, and returned to the students prior to proceeding with electrolytic cell instruction. The overall results showed a good basic understanding of voltaic cells. 
Given a diagram of a voltaic cell consisting of $\mathrm{Al}$ metal in an aluminum ion solution and $\mathrm{Pb}$ in a lead ion solution, a salt bridge and a voltmeter, all 13 students were able to predict which of the two metal electrodes would be oxidized, the direction of electron flow in the external wire, the direction of cation flow in the salt bridge and which electrode increased/decreased in mass over time. In question 2, only two students could not write the correct overall balanced equation for the cell. One of these wrote the half-reactions correctly but did not combine them into one equation as requested. The second student wrote the reverse of the correct equation and included equilibrium arrows. In question 3, three students were unsuccessful at calculating the standard cell potential. One student wrote the voltages and set up the algorithm correctly but made a mathematical error in subtraction. A second student treated the voltages as extensive properties, mistakenly multiplying each voltage by a factor before calculating cell potential by using the correct algorithm. Finally, one student reversed the order of subtraction taking the anode voltage minus the cathode voltage, which was an incorrect algorithm.

Just one student inaccurately predicted what would happen to the concentrations of each of the respective metal ions in the electrolyte in question 8 and 9. It is believed that this was an inadvertent error since this student correctly answered every other question, including which metal is oxidized and which metal ion is reduced.

Question 10 was deleted from this analysis because understanding that the cell voltage approaches zero as the voltaic cell reaches equilibrium is not part of the IB curriculum objectives. 
Questions 11 and 12 asked students to identify which metal electrode was the anode and which was the cathode. Two students reversed these responses despite the fact that they had both previously correctly predicted that the aluminum metal electrode would be oxidized and had written the correct overall reaction. Presumably, these two students did not remember that oxidation occurs at the anode and reduction at the cathode.

Predictably, the worst scores were realized on a question in which students were asked to state which electrode was positively or negatively charged. Four students incorrectly identified the anode as positive and the cathode as negative. Despite this question being related to a specific IB objective (9.4.2 State that in voltaic cells oxidation occurs at the negative electrode (anode) and reduction occurs at the positive electrode (cathode), the assigning of electrode charges was purposely downplayed during lecture. This was done because previous research has shown that a belief that the electrodes carry substantial charges leads to misconceptions and incorrect reasoning in determining the directional movement of various charged particles within the voltaic cell (Ogude \& Bradley, 1996).

\section{Internal Exam Results}

In analyzing the internal exam (Appendix F) results, only those questions related to electrochemistry—either voltaic cells or electrolytic cells—were included, specifically, questions 2,3,4,5,6,10a-e and 11a-g. Results for the multiple-choice questions on the internal exam will be analyzed first, followed by the results for the open-ended questions. 


\section{Multiple-Choice Questions}

Table 1 and Figure 1 show the number and percentage of students who answered each of the multiple-choice questions (questions 2,3,5, and 6) correctly in each of the two years. From the data, it appears that the comparison group performed better on questions 3 and 6 , the experimental group performed better on question 5, and the two groups were relatively the same on question 2 .

Table 1

Results for Questions 2, 3, 5, and 6 from Internal Exam

\begin{tabular}{ccccc}
\hline Question & \multicolumn{2}{c}{$\begin{array}{c}\text { Comparison Group } \\
(\mathrm{n}=18)\end{array}$} & \multicolumn{2}{c}{$\begin{array}{c}\text { Experimental Group } \\
(\mathrm{n}=13)\end{array}$} \\
\hline & $\begin{array}{c}\text { \# students } \\
\text { answering } \\
\text { correct }\end{array}$ & $\begin{array}{c}\text { \% students } \\
\text { answering } \\
\text { correct }\end{array}$ & $\begin{array}{c}\text { \# students } \\
\text { answering } \\
\text { correct }\end{array}$ & $\begin{array}{c}\text { \% students } \\
\text { answering } \\
\text { correct }\end{array}$ \\
\hline 2 & 15 & 83 & 11 & 85 \\
3 & 15 & 83 & 9 & 69 \\
5 & 10 & 56 & 9 & 69 \\
6 & 12 & 67 & 8 & 62 \\
\hline
\end{tabular}

Multiple-choice question 2 asked the student to select the correct statement from the following:

A. Spontaneous reactions produce electricity in an electrolytic cell.

B. Electricity is used to carry out non-spontaneous redox reactions in a voltaic cell.

C. Oxidation takes place at the negative electrode in a voltaic cell and the positive electrode in an electrolytic cell.

D. Oxidation takes place at the negative electrode in a voltaic cell and reduction takes place at the positive electrode in an electrolytic cell 


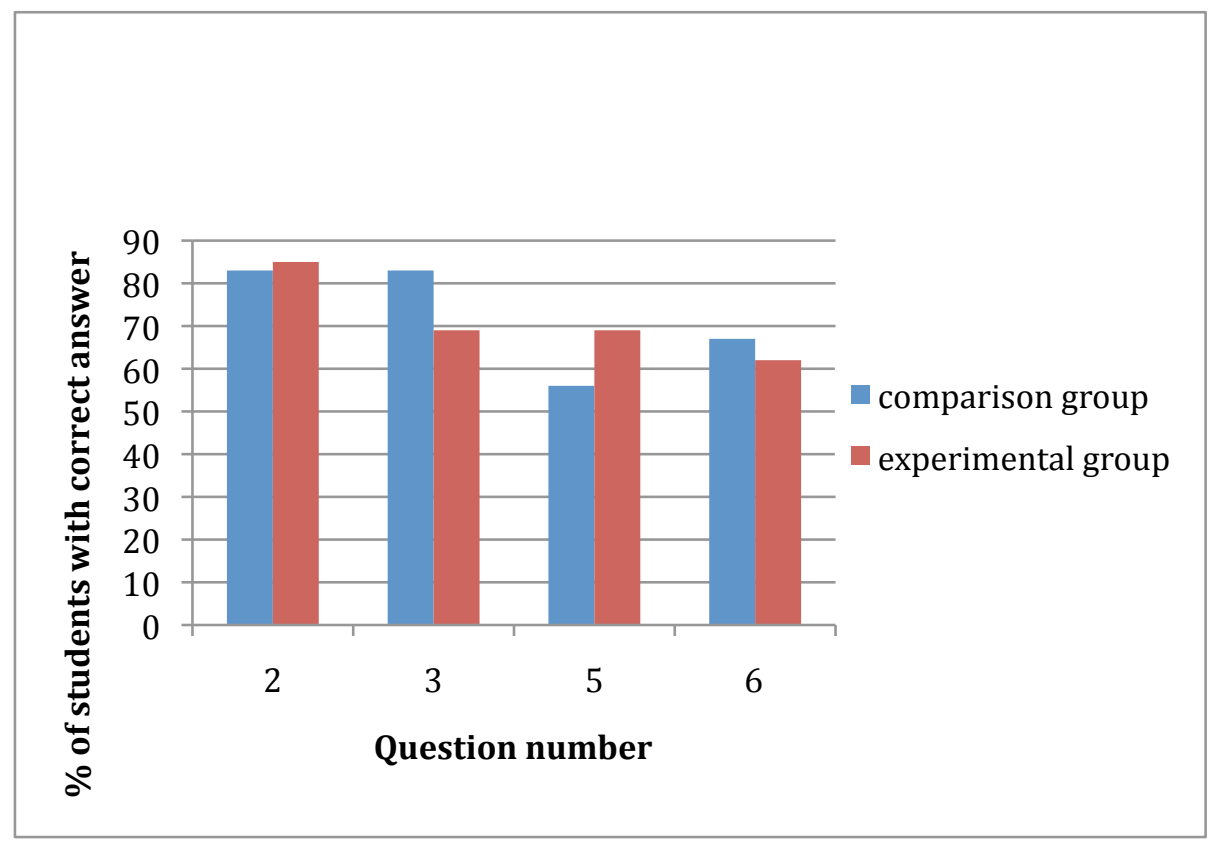

Figure 1.Internal Exam Results for Multiple Choice Questions

Correctly answering this question required understanding of several IB curriculum objectives:

9.4.1 Explain how a redox reaction is used to produce electricity in a voltaic cell.

9.4.2 State that in voltaic cells oxidation occurs at the negative electrode (anode) and reduction occurs at the positive electrode (cathode).

9.5.2 State that in electrolytic cells oxidation occurs at the positive electrode (anode) and reduction occurs at the negative electrode (cathode).

Thus, a correct answer to question 2 required a general understanding of the different purposes of voltaic versus electrolytic cells. It also required that the student understood that oxidation occurs at the negatively charged anode in a voltaic cell and that the charge on the anode is not the same in the voltaic and electrolytic cells. 
The percent of students answering this question correctly stayed constant with $83 \%$ and $85 \%$ answering it correctly over the two years. Apparently, all of the students in both groups understood the difference in purposes of the two types of cells, since incorrect answers A and B were never chosen. The only incorrect answer chosen was $\mathrm{D}$ which could be due to a previously noted common misconception that the negative electrode is always labeled the anode and the positive electrode always labeled the cathode in both types of cells (Sanger \& Greenbowe, 1997a).

Question 3 and 5both related to the relative amounts of gaseous products made at each electrode during the electrolysis of water. The related IB curriculum objective was: 19.2.2 Determine the relative amounts of the products formed during electrolysis. This particular objective was not a priority in the changes made to instruction as part of this project. The percent of students correctly answering question 3 decreased from $83 \%$ to $69 \%$, while the percent correctly answering question 5 improved from $56 \%$ to $69 \%$. Interestingly, despite the fact that the two questions were related to the same chemical reaction (electrolysis of water) and were each answered correctly $69 \%$ of the time by the experimental group of students, only 5 of the 13 students in the group answered both questions correctly. In other words, it can be ascertained that eight experimental group students did not recognize the similarities and relationship between the two questions. This is a potential area of improvement for future instruction and shows a lack of general understanding of chemical equations, moles and Avogadro's theory. 
Question 6 was also related to the above mentioned curriculum objective, 19.2.2, and thus was not emphasized in the changes made to instruction this year. The percent answering this question correctly decreased slightly from $67 \%$ to $62 \%$.

\section{Free-Response Questions}

The free-response questions on the internal exam included questions 4, 10 a-e and 11a-g. The voltaic cell-related question was 10 a-e (see Appendix F) and results for the two groups of students are shown in Figure 2. All five parts of this voltaic cell-related question showed marked improvement from last year to this year. Increases in percent correct answers ranged from an 11\% improvement for question $10 \mathrm{~d}$ to a $36 \%$ improvement for question 10c.

Table 2

Results for Questions 10 a-e from Internal Exam

\begin{tabular}{ccccc}
\hline Question & \multicolumn{2}{c}{$\begin{array}{c}\text { Comparison Group } \\
(\mathrm{n}=18)\end{array}$} & \multicolumn{2}{c}{$\begin{array}{c}\text { Experimental Group } \\
(\mathrm{n}=13)\end{array}$} \\
\hline & $\begin{array}{c}\text { \# students } \\
\text { answering } \\
\text { correct }\end{array}$ & $\begin{array}{c}\text { \% students } \\
\text { answering } \\
\text { correct }\end{array}$ & $\begin{array}{c}\text { \# students } \\
\text { answering } \\
\text { correct }\end{array}$ & $\begin{array}{c}\% \text { students } \\
\text { answering } \\
\text { correct }\end{array}$ \\
\hline $10 \mathrm{a}$ & 8 & 44 & 10 & 77 \\
$10 \mathrm{~b}$ & 14 & 78 & 13 & 100 \\
$10 \mathrm{c}$ & 10 & 56 & 12 & 92 \\
$10 \mathrm{~d}$ & 16 & 89 & 13 & 100 \\
$10 \mathrm{e}$ & 13 & 72 & 12 & 92 \\
\hline
\end{tabular}

Question 10a required students to write two separate half-reactions for a voltaic cell: one for oxidation and one for reduction, given a voltaic cell diagram and the identities of electrode metals and associated metal ions in solutions. Correctly answering this question required that students know that in order to correctly combine the two halfreactions into one chemical equation, equal number of electrons must be lost in the 


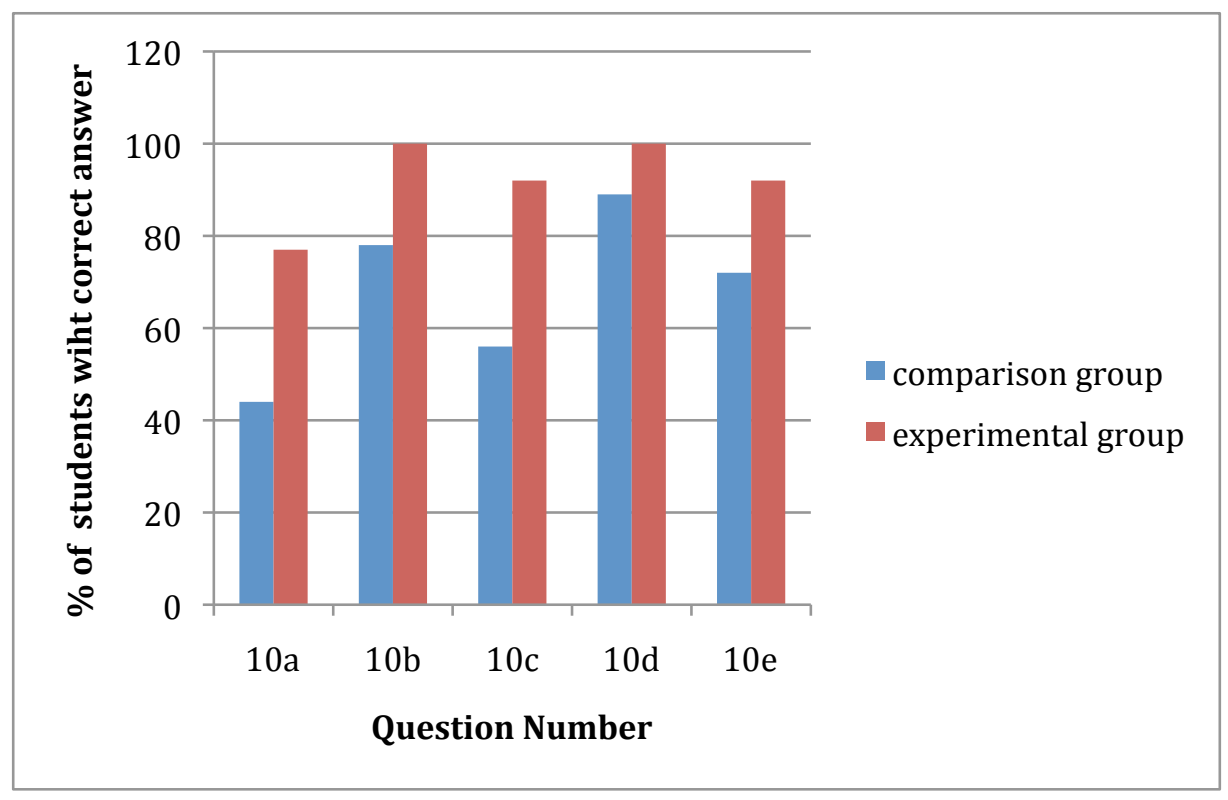

Figure 2. Internal Exam Results for Voltaic Cell Questions (10 a-e)

oxidation reaction and gained in the reduction reaction. Therefore, all species in the reduction half-reaction had to be multiplied by a factor of two before combining the two half-reactions.

Seventy-seven percent of the experimental group answered this question correctly as compared to only $44 \%$ of the comparison group. There were three different types of errors made in question 10a by students in the experimental group. The standard reduction potentials table was available for reference during the test and one student chose to include equilibrium arrows as shown in the table instead of one-way arrows in their half-reactions. This same student had committed the same error on the earlier formative assessment. Presumably, this was done because the half-reactions were copied directly from the reduction potentials table, which uses equilibrium symbols. It is indeed possible for the reactions on this table to occur in either direction, depending on which half-reaction they are paired with in a voltaic cell, but in a voltaic cell the spontaneous 
reaction occurs in one direction only. This possible pitfall was specifically discussed in lecture by the instructor who was cognizant of the fact that students from the comparison group had lost multiple points on the previous year's IB external exam for using equilibrium arrows. The difficulty here appears to be in understanding the relative nature of the voltages and half-reactions on the standard reduction potentials table. This difficulty was also made obvious to the instructor in a one-on-one review discussion with another experimental group student who could not understand why both hydrogen gas and $\mathrm{H}^{+}$ions must be available in the standard hydrogen electrode half-cell until it was pointed out that this reaction may be required to run in either direction, depending on the identity of the other half-cell.

A second student from the experimental group chose the wrong half-reaction for iron oxidation, including a $\mathrm{Fe}^{3+}$ ion that was not part of the cell in question. A third student correctly wrote each of the half-reactions but did not complete the question by combining them into one equation as requested. This may have been a language issue, as this student's primary language was Vietnamese. With the exception of the use of equilibrium arrows, students in the comparison group made these same errors on the previous year's internal exam. Interestingly, an error that was prevalent last year but not this year was that five students in the comparison group neglected to multiply the reduction half-reaction by a factor of two before combining the half-reactions; this error did not occur among the experimental group students.

Question 10b required the student to state "standard conditions" as defined in electrochemistry and simply required that the students use a memorized set of facts. All 
students in the experimental group got this question correct versus only $78 \%$ of the comparison group. A common error last year was that students mentioned temperature and pressure conditions but forgot to include the stipulation of 1.0 molar concentration for the electrolyte solutions. This is an understandable oversight because standard temperature and pressure conditions was established knowledge as these had been defined in previous chapters of study on energetics and gas laws, but the stipulation of a specific solution concentration is unique to the study of electrochemistry.

Results for question 10c showed a marked improvement from $56 \%$ in the previous year to $92 \%$ correct in the experimental group. This question is directly related to curriculum objective19.1.3: Calculate cell potentials using standard electrode potentials. Answering question 10c correctly required that the student must either memorize an algorithm used to find voltaic cell voltage potential $\left(\mathrm{E}^{\circ}\right.$ cell $=\mathrm{E}^{\circ}$ cathode $-\mathrm{E}^{\circ}$ anode $)$, or alternatively, must have an understanding of the relative nature of the standard reduction potential table and thus understand how to mathematically manipulate the sign on the standard half-cell voltage if the reaction is reversed. For this particular set of half-cells, a correct answer also required that a student understand the intensive nature of the voltages shown on the standard reduction table. Specifically, a student needed to understand that regardless of whether or not a half-reaction must be multiplied by a numerical factor in order to combine and balance half-reactions, the voltage for a given half-reaction remains constant.

The only student in the experimental group who missed this question was the student who had chosen the wrong half-reaction in question 10a. Despite this, the student 
did perform the algorithm correctly using an incorrect voltage value. In comparison, the comparison groups' errors were frequent and varied, with only $56 \%$ answering correctly. Comparison group errors included mathematical mistakes, subtracting voltages in the wrong order, adding instead of subtracting the voltage table values, and treating voltages as extensive properties.

Question 10d required the students to indicate the correct direction of electron flow on a diagram. This question is related to the following objective: 9.4.1 Explain how a redox reaction is used to produce electricity in a voltaic cell. To correctly answer this question, the student needed to understand that the electrons flow through the external wire from the electrode where oxidation takes place to the electrode where reduction takes place. Every student (100\%) in the experimental group answered this question correctly versus $89 \%$ of the comparison group. This result was particularly encouraging since the visualization and computer simulation exercises added to instruction were meant to help the students better understand sub-microscopic directional movement.

Unfortunately, the IB test question showed the anode located on the left side of the diagram, as is often the case in textbook examples, so it was not possible to determine if any students held the common misconception that the anode of a voltaic cell is that which is drawn on the left side (Sanger \& Greenbowe, 1997a). In order to check for the existence of this misconception, the half-cell locations would need to be reversed on future tests.

Question 10e asked students to annotate a voltaic cell drawing with the direction of flow for both cations and anions through the salt bridge. This question is related to the 
objective: 9.4.1 Explain how a redox reaction is used to produce electricity in a voltaic cell.

Only one student ( $92 \%$ correct) in the experimental group missed this question whereas five students $(72 \%$ correct) missed this question in the previous year. Again, this improved result was particularly encouraging since the visualization and computer simulation exercises added to voltaic cell instruction were meant to help the students better understand sub-microscopic directional movement. Also, the misconceptions prevalent in this area were discussed in lecture with an emphasis placed on the purpose of salt bridge ion movement being to maintain electrical neutrality in each respective halfcell. The one experimental student who missed this question showed cations migrating toward the anode and anions migrating toward the cathode. Three of the comparison students had committed the same error. The reason for this error could be due to a previously documented misconception (Garnett \& Treagust, 1992) that because the anode is negatively charged it attracts positive cations and because the cathode is positively charged it attracts negative anions. It was this misconception that the instructor had hoped to avoid by not emphasizing the small charges present on each electrode in the voltaic cell (Ogude \& Bradley, 1996). The other two comparison group students who missed this question showed arrows in the salt bridge pointing in only one direction, as if both cations and anions flowed in the same direction.

Questions 4 and 11a-g will be discussed together since they are both related to electrolytic cells. Recall that some of the instructional changes planned for this topic were not implemented due to limited class time. Student did not have chance to manipulate 
electrolytic cell physical models, but instead, observed a short teacher demonstration. Also, no computer simulation exercise was done. In general, there was less consistent improvement in the percent correct between the comparison and experimental groups results for this topic versus voltaic cells, although the experimental group did outperform the comparison group on five of the eight questions.

Table 3

Results for Question 4 and 11 a-g from Internal Exam

\begin{tabular}{ccccc}
\hline Question & \multicolumn{2}{c}{$\begin{array}{c}\text { Comparison Group } \\
(\mathrm{n}=18)\end{array}$} & \multicolumn{2}{c}{$\begin{array}{c}\text { Experimental Group } \\
(\mathrm{n}=13)\end{array}$} \\
\hline & $\begin{array}{c}\text { \# students } \\
\text { answering } \\
\text { correct }\end{array}$ & $\begin{array}{c}\text { \% students } \\
\text { answering } \\
\text { correct }\end{array}$ & $\begin{array}{c}\text { \# students } \\
\text { answering } \\
\text { correct }\end{array}$ & $\begin{array}{c}\text { \% students } \\
\text { answering } \\
\text { correct }\end{array}$ \\
\hline 4 & 10 & 56 & 8 & 62 \\
$11 \mathrm{a}$ & 9 & 50 & 6 & 46 \\
$11 \mathrm{~b}$ & 11 & 61 & 6 & 46 \\
$11 \mathrm{c}$ & 2 & 11 & 4 & 31 \\
$11 \mathrm{~d}$ & 10 & 56 & 9 & 69 \\
$11 \mathrm{e}$ & 9 & 50 & 6 & 46 \\
$11 \mathrm{f}$ & 4 & 22 & 6 & 46 \\
$11 \mathrm{~g}$ & 10 & 56 & 12 & 92 \\
\hline
\end{tabular}

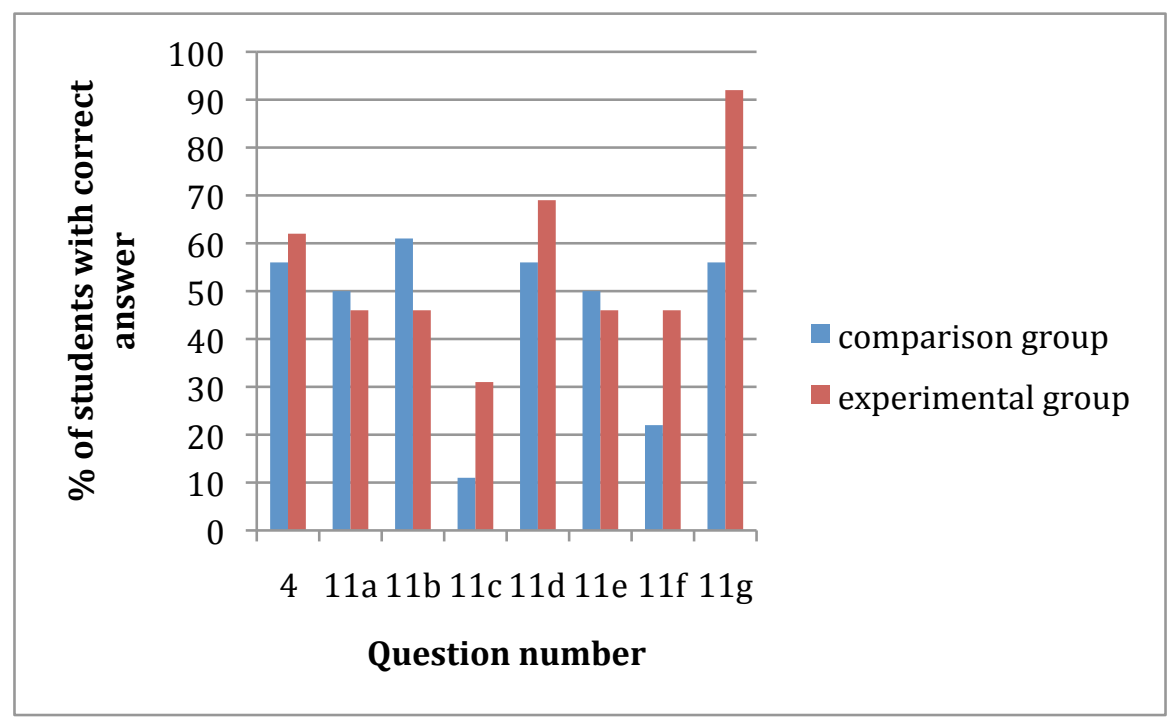

Figure 3. Internal Exam Results on Electrolytic Cell Questions (4, 11 a-g) 
Question 4 asked why it might be necessary to acidify water in electrolysis and was related to the following objective: 9.5.3 Describe how current is conducted in an electrolytic cell. Specifically, correctly answering this question required that students understand that a sufficient concentration of mobile positive and negative ions are required in the electrolyte in order for electricity to be conducted. According to researchers (e.g., Sanger \& Greenbowe, 1997a), this is an area fraught with misconceptions, as many students believe that electricity can only be conducted through movement of delocalized electrons. In the case of pure water as an electrolyte, there is another secondary opportunity for a misconception that has been noted by this instructor: many high school juniors mistakenly believe that pure water is a good electrical conductor. This misconception results from their life experiences: general warnings about not swimming during lightning storms and the safety tags warning about not immersing a portable hair dryer into the bathtub water. Therefore, student responses to question 4 were scrutinized for evidence of these misconceptions.

The percent of students who answered question 4 correctly increased slightly from $56 \%$ to $62 \%$. Eight of the thirteen students in the experimental group acknowledged that pure water contains very few free ions and therefore, acid addition was necessary to supply ions for conduction. As one student put it, "Because pure $\mathrm{H}_{2} \mathrm{O}$ cannot conduct via mobile ions- it needs to be in solution with impure substances. In this case, $\mathrm{H}^{+}$ions." Several students specifically mentioned the contribution of $\mathrm{H}^{+}$ions from the addition of acid, but none mentioned that the acid also contributed negatively charged ions. It is possible that there may be a misconception that the addition of just one type of charged 
ion with a positive charge is all that is necessary to complete conduction and that both types of charged ions are not necessary. Sanger and Greenbowe (1997a) reported a similar misconception that some students believed that cations in the salt bridge and in the electrolyte were capable of accepting electrons and transferring them from the cathode to the anode, thereby completing the electrical circuit.

In answering question 4, two of the experimental students confused cause and effect, stating that the reduction of water, which occurs at the cathode electrode, would put more $\mathrm{OH}^{-}$ions into the electrolyte as one of the byproducts of the reaction. These students further hypothesized that the acidification of the water was necessary to

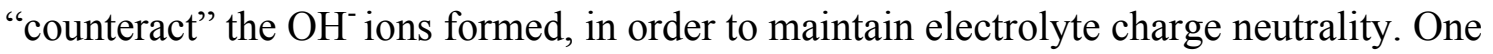
student stated that the reason for acid addition was, "Because the $\mathrm{H}_{2} \mathrm{O}$ will produce $\mathrm{OH}^{-}$, a base, and the solution must be neutral." And, another said, "splitting up $\mathrm{H}_{2} \mathrm{O}$ leaves $\mathrm{OH}^{-}$in the solution. So water should be acidic to neutralize the basic result." It is not clear as to whether these students meant neutrality in terms of charge or $\mathrm{pH}$, but most likely they are referring to charge and maintaining equal numbers of positive and negative ions in the electrolyte since that criterion was emphasized in lecture. These two students neglected to consider that the oxidation of water at the anode electrode would produce the $\mathrm{H}^{+}$ions needed to cancel out the $\mathrm{OH}^{-}$ions from the cathode and maintain electrolyte charge neutrality. Thus, additional acidification of the electrolyte is not necessary to maintain electrical neutrality. Interestingly, no students in either of the two groups mentioned the existence of delocalized electrons in the electrolyte, which is a commonly reported misconception (Huddle, White, \& Rogers, 2000). 
In question 11, parts a, b, c, e, and f concerned the electrolysis of an aqueous ionic solution and were related to the following curriculum objectives:

9.5.2 State that in electrolytic cells oxidation occurs at the positive electrode (anode) and reduction occurs at the negative electrode (cathode).

19.2.1 Predict and explain the products of electrolysis of aqueous solutions. For students to answer these questions correctly, they must understand that with an aqueous electrolyte, it is also possible for water to be preferentially oxidized or reduced. In other words, in this scenario, it is the water that is preferentially oxidized at the anode, forming oxygen gas before the electrolyte nonmetal anion is oxidized. (And depending on the circumstances, it is also possible in some situations, for the water to be reduced at the cathode forming hydrogen gas instead of the electrolyte metal cation being reduced.) This is a more complex situation than what occurs in a molten salt electrolyte where water is not present and no decision must be made in predicting the product at each electrode. An aqueous solution electrolyte requires the student to use criteria to decide which of several possible products will be produced at each electrode. The students must also understand how to use the standard reduction potentials table to decide which reaction preferentially occurs and at which electrode. In addition, question 11e required the student to know that a very concentrated aqueous ionic electrolyte (e.g., $\left.\mathrm{CuCl}_{2}\right)$ might cause this normal preference to change.

Question 11a and $11 \mathrm{~b}$ asked students to identify what reaction would occur at the positive electrode (11a) and negative electrode (11b) of an electrolytic cell with an aqueous electrolyte solution of $\mathrm{CuSO}_{4}$ and platinum (inert) electrodes. The percent of 
students who answered these questions correctly decreased over the two years, from $50 \%$ to $46 \%$ for $11 \mathrm{a}$ and from $61 \%$ to $46 \%$ for $11 \mathrm{~b}$.These are discouraging results given that a new algorithm was taught in lecture in order to help students correctly determine what product would be made at each electrode with an aqueous electrolyte.

When answering question 11a, comparison students made many different errors. Three of these students responded incorrectly with a half-reaction showing the oxidation of solid copper, yet according to the question, there was no solid copper available in the cell. Presumably these students recognized that oxidation occurs at the anode and that platinum would not react, but did not consider the possibility of water being oxidized. When answering question 11a, three other comparison group students copied a reduction half-reaction from the standard reduction table, incorrectly stating that the sulfate ion, $\mathrm{SO}_{4}^{-2}$, would reduce to form $\mathrm{H}_{2} \mathrm{SO}_{3}$ (aq) at the positive electrode. Either these students did not understand that oxidation occurs at the positive electrode (anode) in electrolysis or they did not recognize that the reaction they wrote was a reduction reaction. Choosing the $\mathrm{SO}_{4}{ }^{2-}$ ion as the species to be oxidized, though incorrect, was a somewhat understandable error from the standpoint that in a molten salt electrolytic cell, it is generally the electrolyte anion that is oxidized at the anode. Three comparison students also incorrectly included equilibrium arrows in their half-reactions.

The experimental group also did poorly with questions $11 \mathrm{a}$ and $11 \mathrm{~b}$ but, on a positive note, $100 \%$ of the experimental group included water as a possible reactant, albeit sometimes incorrectly. For example, two students had both half-reactions written correctly but reversed the electrode at which each would occur. One experimental student 
stated that both copper +2 ions and water would be reduced at the cathode, not taking into account the exclusivity of the process. Yet another student stated that water would be both oxidized at the anode and also reduced at the cathode, ignoring the presence of the more easily reduced $\mathrm{Cu}^{2+}$ ion.

Question 11c was answered correctly only $11 \%$ of the time by the comparison group and $30 \%$ by the experimental group. This question asked students to state observable changes in the electrolyte during electrolysis and was not directly related to any specific electrochemistry chapter objective, but called upon students' background chemical knowledge. A correct answer to 11c was also dependent upon correctly answering the two previous questions, $11 \mathrm{a}$ and $11 \mathrm{~b}$. An error commonly made by both groups was to state inferences instead of observable phenomena. For example, students would correctly state that $\mathrm{Cu}^{2+}$ ion concentration would decrease in the electrolyte but would not state the observation that this would cause the characteristic blue color of the electrolyte to fade. Another common error was to state what would occur at the electrodes instead of within the electrolyte. For example, "oxygen gas bubbles formed on the platinum anode and solid copper formed on the platinum cathode." These types of errors might be a matter of either not knowing the terminology used or not clearly understanding what the question was asking.

Question 11e asked what difference there would be in the products formed at each of the electrodes of the previously described electrolytic cell if the electrolyte was concentrated $\mathrm{CuCl}_{2}$ instead of $\mathrm{CuSO}_{4}$. This question is related to a memorized exception to the general rule taught in the algorithm, which states that species on the top-right of the 
standard reduction table will be oxidized before those species on the bottom right. Specifically, students were asked to memorize the fact that concentrating the chloride ion in an aqueous solution results in the $\mathrm{Cl}^{1-}$ ion oxidizing more easily than water, despite the relative positions of these two species on the standard reduction table. (The reasons for this exception are beyond the scope of this course.) Fifty percent of the comparison group and $46 \%$ of the experimental group answered this question correctly. Errors found in the responses of both groups included several students who predicted the correct products but at the incorrect electrodes. Also, several students stated there would be no change in their original prediction of the products to be formed upon the introduction of the concentrated chloride ion and several students mentioned chlorine atoms (or ions) being produced at the anode, but did not correctly predict the actual product (chlorine diatomic gas) which would form.

Question 11f returned to the original electrolytic cell proposed in question 11a and $11 \mathrm{~b}$ and asked what would occur, at the electrodes and in the electrolyte, if the inert platinum electrodes were replaced with copper metal electrodes. This refers to a specific, real-life application of electrolysis discussed in lecture in which the electrolytic cell is used for the purification of copper. Since copper metal is more easily oxidized than water, replacing the non-reactive platinum anode with copper metal introduces a new species available for oxidation: solid copper. Using the newly introduced algorithm which predicts that the top-right side species on the reduction table is most easily oxidized, introducing copper metal means that instead of water being oxidized into oxygen gas at the anode as it was in question 11a, the copper metal anode will be 
oxidized into copper ions which will travel through the aqueous electrolyte and be reduced onto the (-) cathode as solid copper. Thus, as the impure copper anode is eroded away, purified solid copper is collected on the cathode with the copper metal anode continually replenishing copper ions in the electrolyte solution. This is a somewhat unusual circumstance since copper is being both oxidized and reduced in a single cell but this is predictable using the instructional algorithm.

In the comparison group, only $22 \%$ answered $11 \mathrm{f}$ correctly. The incorrect answers were either because the students predicted no change (from the prediction in 11a) in the anode product that would be formed with the introduction of solid copper, or because the student mixed up which process occurs at which electrode; that is, a student would incorrectly state that reduction would occur at the anode and oxidation at the cathode. In the experimental group, $46 \%$ answered question $11 \mathrm{f}$ correctly. On a positive note, all of the experimental students acknowledged the change in anode product, stating that copper would be oxidized instead of water. Thus, the introduction of an algorithm for making decisions about electrode products may have helped improve this result. Low percentage scores were mainly due to errors of omission for missing information in the description, for example, not explaining what observable changes occur at both of the electrodes and within the electrolyte.

The last two parts of question $11,11 \mathrm{~d}$ and $11 \mathrm{~g}$, were related to an objective that was not a target for this study (19.2.2 Determine the relative amounts of the products formed during electrolysis). However, the percent correct for each question realized some 
improvement between the comparison and experimental groups. Question 11d results improved from $56 \%$ to $69 \%$ correct and $11 \mathrm{~g}$ improved from $56 \%$ to $92 \%$ correct.

\section{External Exam Question Results}

In May 2010, 9 of 18 comparison group students had chosen to answer an optional, free-response question on the topic of electrochemistry on the IB external exam (Appendix G). Their externally scored tests and the rubric used by the IB grader were in the possession of the instructor. To gather more data for comparison purposes, approximately one week before the May 2011 IB external exam was to be taken by the experimental group, the same free-response electrochemistry question was given to the experimental group of students to answer. The experimental group was told that their individual grades would not be counted toward their final class grade but were asked to do their best as this data was to be used in this research project.

The four main parts of the question were awarded anywhere from three to ten points according to the IB-created rubric. The average points scored in each part by each of the two groups were calculated as percentages. The average percentage achieved and the standard deviation for each part of the question are shown in Table 4 below. The table shows the results for the nine comparison group students who voluntarily chose to answer this question, and the thirteen experimental group students. It should be noted that two of the experimental students had already notified the instructor that they did not intend to take the IB external exam. Additionally, two of the remaining eleven experimental students were planning to take the less rigorous standard-level exam instead of the higher-level exam. Thus, experimental group results were calculated a second time 
removing those four students from the data set since it can be assumed that their level of review in preparation for the external exam would be less.

Table 4

Results for Questions 6 a-d from 2010 IB External Exam

\begin{tabular}{|c|c|c|c|c|c|c|c|}
\hline \multirow[t]{2}{*}{ Question } & \multirow[t]{2}{*}{ Topic } & \multicolumn{2}{|c|}{$\begin{array}{l}\text { Comparison } \\
\text { group }\end{array}$} & \multicolumn{2}{|c|}{$\begin{array}{l}\text { Experimental } \\
\text { group }\end{array}$} & \multicolumn{2}{|c|}{$\begin{array}{l}\text { *Higher Level } \\
\text { IB exam takers }\end{array}$} \\
\hline & & Avg & SD & Avg & SD & Avg & SD \\
\hline $6 \mathrm{a}$ & Voltaic Cells & 51.4 & 24.5 & 55.6 & 29.7 & 66.4 & 22.8 \\
\hline $6 b$ & Standard reduction potentials & 14.7 & 24.0 & 23.1 & 28.6 & 26.0 & 32.5 \\
\hline $6 c$ & Standard Hydrogen Electrode & 50.0 & 35.4 & 25.0 & 36.8 & 36.3 & 39.5 \\
\hline $6 \mathrm{~d}$ & Electrolytic Cells & 13.3 & 16.6 & 11.5 & 12.1 & 12.2 & 13.0 \\
\hline
\end{tabular}

The first part of external exam, question 6a, required the students to draw an annotated diagram of a voltaic cell given a written description specifying electrode metals and associated electrolyte half-cell solutions. The labeled diagram needed to include the two half-cells with electrode and electrolyte solutions, a salt bridge, a voltmeter and the direction of electron flow in the external wire. Question 6a then asked the student to write out the two relevant half-reactions and to calculate a cell potential using the standard reduction potentials table. The particular half-reactions chosen required that students understand the intensive nature of half-cell potential. For this question, results were consistent (about 52\% correct) between the comparison and experimental groups, with those experimental students intending to take the higher-level IB exam scoring, on average, about $10 \%$ higher.

Errors seen in the diagrams drawn by the comparison group included several instances of incorrect electron flow direction and missing salt bridges and voltmeters. Because the question was worded such that the electrodes and electrolyte solutions were 
specifically mentioned, but the existence of the salt bridge and voltmeter were not mentioned, these omissions are understandable. Despite the physical model manipulation and computer simulations done several months earlier, the experimental group also had three students who omitted the voltmeter in their diagrams and one student who omitted the salt bridge. Three experimental students also diagrammed electron flow in the wrong direction or not at all. Thus, the visualization practice seemed to result in only a shortterm improvement in remembering sub-microscopic particle directional movement.

Additionally, a new phenomenon that was not observed in the comparison group (or on the internal exam) was that four experimental students incorrectly substituted a battery symbol as would be found in an electrolytic cell for the voltmeter normally found in the voltaic cell. Interestingly, although only three students had made this error on the earlier internal exam, six of the nine comparison students wrote equilibrium arrows instead of one-way arrows in their half-reactions on the external exam. An increase was also seen among the experimental students with four students instead of just one incorrectly showing equilibrium arrows in their half-reactions, despite specific warnings regarding this error from the lecturer. The instructor believes this error is not due to any actual misconception because these same students could correctly identify the one-way directional movement of metal atoms (and ions) and the outcomes of this movement in a voltaic cell. Rather, it is believed that this oversight is due to the students relying on copying the standard reduction table reactions without a good understanding of the relative nature of this table. Perhaps, it also highlights a lack of understanding of the equilibrium phenomenon that exists between the electrode metal and its electrolyte 
solution in an individual half-cell before it is placed in an electrical circuit with another half-cell.

According to the IB scoring rubric, points were also deducted on the second part of question $6 \mathrm{a}$ for not labeling each half-reaction as to whether it was oxidation or reduction. In this instructor's opinion, this last expectation was not clearly spelled out in IB's wording of the question as evidenced by the fact that only two students in each of the two groups labeled their half-reactions as to whether they were oxidation or reduction. Yet there were many more students who actually had written both halfreactions correctly.

In part three of question $6 \mathrm{a}$, the cell potential was calculated using the standard reduction potentials table as a reference for finding half-cell voltage potentials. The comparison and experimental students committed the same types of errors when calculating the overall cell voltage. All but one of the students in both groups who attempted to answer the question understood that the voltage potentials of the two halfreactions should be subtracted, but either the order of operations was not correct or additional negative signs were introduced (see Figure 4).

\begin{tabular}{|c|c|}
\hline Correct: & $\mathrm{E}_{\text {cathode }}-\mathrm{E}_{\text {anode }}=\mathrm{E}_{\text {cell }}$ \\
\hline \multirow[t]{2}{*}{ Incorrect: } & $E_{\text {anode }}-E_{\text {cathode }}=E_{\text {cell }}$, or \\
\hline & $(-) E_{\text {anode }}-E_{\text {cathode }}=E_{\text {cell }}$ \\
\hline
\end{tabular}

Figure 4. Common Student Errors when Calculating Cell Potential 
As a result of these errors, three comparison group students and two experimental group students reported a negative cell potential, apparently not realizing that a negative cell potential value would indicate a non-spontaneous overall reaction and thus, an inoperable voltaic cell. On a positive note, only one student multiplied the standard reduction table voltage by a factor, forgetting the intensive nature of the table voltage values, and only one student added both half-reaction voltages. Both of these misconceptions have previously been noted by other researchers (Sanger \& Greenbowe, 1997a).

Question $6 \mathrm{~b}$ required the student to identify the species which would be the best reducing agent (i.e., most easily oxidized) given three half-reactions and associated voltages from the standard reduction potential table. The presentation of the given halfreactions was not in their usual order but scrambled as compared to that of a normal table. Thus, though not directly related to a specific voltaic cell formation, correctly answering this question required a good understanding of the standard reduction potentials table and how to manipulate the data. The second part of question $6 \mathrm{~b}$ required the student to choose which two of the three reactions would result in the greatest possible voltaic cell potential and manipulate the half-reactions into a single, balanced reaction. This external exam question was related only indirectly to the emphasis of this study, yet the experimental group $(23.1 \%$ overall; $26 \%$ for those taking the higher level IB exam) outscored the control group (14.7\%) so there may have been some unexpected benefits realized from the changes in instruction. In fact, the experimental group's average score could have been better than $23.1 \%$ except that three of the thirteen students 
apparently misunderstood the question. Those three students wrote out the half-reaction containing the most easily oxidized species instead of just identifying the single, easily oxidized atom/ion species within that half-reaction.

Question 6c asked students to describe the materials and conditions in a standard hydrogen electrode (SHE). A diagram was optional. The comparison group (50\%) did much better than the experimental group (25\%) on this question. Six of the thirteen experimental students, however, did not attempt to answer this question, which relates directly to one of the IB electrochemistry objectives: 19.1.1 Describe the standard hydrogen electrode. This instructor believes that the reason for the lack of attempts to answer and the poor results among the experimental students was because the answer is a memorized set of facts. Thus, because they had not reviewed this particular material recently, many of the experimental students did not try to answer what should have been a relatively simple question. In support of this idea, the subset of experimental students who were undergoing more intense preparation for the higher-level exam did score $10 \%$ higher (36\%) than the experimental group as a whole (25\%). The comparison group students may have achieved better results because they answered this question while taking the actual IB external exam following a period of intense review preparation.

The last part of the question (6d) focused on electrolytic cells. Comparison and experimental groups performed consistently but poorly on this question, achieving only $13.3 \%$ and $11.5 \%$ of the points, respectively. Recall that some of the instructional changes planned for this topic were not implemented due to limited class time. Student did not have chance to manipulate electrolytic cell physical models but instead observed 
a short teacher demonstration. Also, no computer simulation exercise was done. Three of the thirteen experimental students did not complete any part of this three-part question, indicating that they may have run out of time. The first part of question $6 \mathrm{~d}$ was not specific to electrolytic cells, but generally, to the properties of molten versus solid, ionically-bonded salts that allow for electrical conductivity. Conductive properties had been studied in another earlier chapter on bonding.

In order to be awarded all of the possible points, the student had to mention the presence of ions locked into a lattice in a solid salt and mobile ions in a molten salt. Use of general terms, such as charged particles, did not result in the awarding of full points, nor were technically incorrect terms, such as molecules or atoms, accepted. Two comparison students and two experimental students incorrectly described the existence of mobile electrons in the molten salt as the reason for its conductive properties. This occurred despite explicit explanations given to the experimental group regarding this common misconception. One experimental student stated, "molten sodium chloride is able to conduct electricity because the electrons are freely moving. There are delocalized electrons that are able to conduct." A second experimental student included both possibilities, stating, "the molten state allows the ions/electrons to be free to move." This is a well-documented, persistent, common misconception among students who believe that movement of electrons is the only method by which electricity is conducted (e.g., Garnett \& Treagust, 1992). 
The second part of question $6 \mathrm{~d}$ asked the student to outline what happens in an electrolytic cell of molten sodium chloride using inert electrodes. This question relates to several IB objectives targeted in this study:

9.5.2 State that in electrolytic cells oxidation occurs at the positive electrode (anode) and reduction occurs at the negative electrode (cathode).

9.5.3 Describe how current is conducted in an electrolytic cell.

9.5.4 Deduce the products of the electrolysis of a molten salt.

The full awarding of points required correctly describing in terms of each electrode (a) the migratory path of the cations and anions in the molten salt, (b) where oxidation and reduction reactions would occur, respectively, and (c) the half-reactions resulting.

Only five of the 13 experimental students attempted to answer the last two parts of question $6 \mathrm{~d}$, probably due to lack of time. Three of those five students correctly predicted that sodium ions $\left(\mathrm{Na}^{1+}\right)$ would be reduced to sodium metal but did not state at which electrode the half-reaction would occur. Only one of the five who answered correctly stated that chloride ions $\left(\mathrm{Cl}^{1-}\right)$ would be oxidized into diatomic chlorine gas, though three others wrote some sort of incorrect half-reactions involving chloride ions. Only three students actually wrote out the half-reactions as requested and none used equilibrium arrows. The facts that so few students correctly predicted the diatomic chlorine gas product and that none included equilibrium arrows might indicate that the students did not consult the standard reduction potentials table when answering this question. 
By comparison, six of the nine comparison group students attempted the last two parts of question 6. Four of the six attempted to write out half-reactions but only two correctly specified at which electrode each reaction would take place. Only one comparison student correctly wrote out both half-reactions, including correctly predicting diatomic chlorine gas product at the anode. Unfortunately, this same student lost points for including equilibrium arrows in the half-reaction. In total, two of the comparison students incorrectly included equilibrium arrows in their half-reactions.

The last part of question 6 related to an IB objective that was not a focus of this study (19.2.2 Determine the relative amounts of the products formed during electrolysis) and so will not be discussed here.

\section{Experimental Student Survey on External Exam Questions}

In May 2011, 9 of the 13 experimental group students took the IB higher-level external exam and, when given the opportunity to answer two of four free-response questions on various chemistry topics, eight of these students chose to answer the question on oxidation-reduction and electrochemistry. The other optional topics were about bonding, organic chemistry, and acids and bases. The one experimental student who did not choose to answer the electrochemistry question had been absent on the first day that electrolytic cells were introduced in class and was admittedly less comfortable with the topic. In the previous year, 9 of 16 comparison students who took the IB higher level exam had chosen to answer the electrochemistry-related question earning anywhere from 12 to $60 \%$ of the available points. 


\section{Summary}

In summary, the changes made to electrochemistry instruction appeared to improve test results, especially in the area of voltaic cells, with a more substantial improvement noted in the short-term on formative and internal exam results. Several misconceptions and error types were persistent and reappeared with greater frequency after a time delay. Yet the experimental students' confidence in their knowledge and attitude towards electrochemistry appeared stronger than that of the comparison group. These results and their implications will be discussed in greater detail in the following chapter. 


\section{Chapter 5}

\section{Summary and Conclusions}

\section{Overview of Research Results}

\section{Voltaic Cells}

After reviewing student results on both the internal and external exams, it was found that in the short-term, student understanding of voltaic cells for the experimental group had substantially improved from the understanding demonstrated by the comparison group. Recall that with the experimental group, common misconceptions found among students were explicitly addressed during lectures. In addition, student manipulation of a physical model voltaic cell representation - complete with electrode and electrolyte chambers, a salt bridge divider, a "wire" to allow for external electron movement and movable atoms/ions with removable electrons - was incorporated into the voltaic cell segment of the chapter and students were taken into a computer lab to observe and manipulate a computer simulation of a voltaic cell.

Results from the internal exam administered immediately after instruction showed improvements that ranged from $11 \%$ to $36 \%$ more of the experimental students correctly answering each of the five parts of the exam question related to voltaic cells compared to the comparison group. However, the external exam administered after a delay of several months showed only a slight improvement between the comparison and experimental groups, both of which scored about $50-55 \%$ of the possible points. It can be argued that a fairer comparison could be drawn between the comparison group and the subset of 
experimental students intending to take the IB higher-level exam, since these groups of students had spent similar amounts of time preparing for the IB exam. For this subset of experimental group students, there was $15 \%$ improvement in performance on the voltaic cell question over the comparison student group.

It is impossible to know whether the apparent improvement in short-term voltaic cell understanding was solely due to the above instructional changes. The improvement could also be attributed to the frequent review of voltaic cells mandated by the large number of classroom interruptions that occurred during the instruction period or, perhaps, to the innate abilities and interests of the students in the experimental group. In any case, the results did show an improved understanding of voltaic cells for the experimental group.

\section{Electrolytic Cells}

The time spent on electrolytic cell instruction was admittedly rushed and compromises were made to the original lesson plan in order to allow time to complete the entire IB curriculum prior to the May external exam. A difficulty with instruction about electrolytic cells following that of voltaic cells is that there are some similarities between the two types of cells, but there are also some important differences. Keeping this information correctly organized in the students' minds is a challenge.

Misconceptions in this area were addressed during lecture over the course of two days, but there was no time for hands-on student manipulation of the physical model of an electrolytic cell as was intended. Instead, a short, teacher-led demonstration was held using a single model to show how the process of copper metal purification might be 
accomplished using electrolysis. Students did not an opportunity to observe or work with a computer simulation. Less than one 45 minute class period was spent practicing a newly introduced instructional algorithm that was intended to help students correctly determine which products would be made at each electrode in an aqueous solution electrolytic cell.

The data showed that changes in student understanding of electrolytic cells between the comparison and experimental groups were mixed. Immediately following instruction, the internal exam results showed improvement on five of the eight electrolytic cell-related questions. Improvements from the comparison to the experimental group in the number of students answering these questions correctly ranged from $6 \%$ to $36 \%$. For the remaining three electrolytic cell questions, the number of students answering correctly decreased between $4 \%$ and $15 \%$. Performance on external exam electrolytic questions decreased slightly, from the comparison students earning $13.3 \%$ of the possible points to $11.5 \%$ of possible points for the experimental group. The subset of experimental group students intending to take the IB higher-level exam scored only slightly better than the experimental group as a whole, achieving $12.2 \%$ of the points.

Although the scores for both groups of students on the external exam questions were poor, preparation may have affected the experimental group's results. Recall that the experimental group was asked to answer the external exam question three months after instruction occurred without prior warning or review time. The comparison group, on the other hand, had presumably prepared intensely for the actual external exam and 
had the option to choose whether to answer this question. Only nine of the sixteen students chose to do so, indicating that the others were probably not confident about this topic. If the entire comparison group had been required to answer the electrochemistryrelated question, the average score would have likely been even lower. Furthermore, perhaps with more timely review and preparation, the experimental group's results might have been better.

On a positive note, the time spent teaching the new algorithm for determining electrolytic cell products to the experimental group seemed to make that group's errors more consistent and understandable than those of the comparison group. For example, when asked to predict what the products would be at the electrodes of an aqueous electrolytic cell, every student in the experimental group made mention of the possibility of water being preferentially oxidized or reduced at the electrodes. This is important because it clearly shows that the experimental students had considered this possibility. On the other hand, the comparison group's incorrect answers were more random and varied, with several students not acknowledging water's ability to react. It is possible that more time spent practicing the newly introduced algorithm might have solidified the experimental group's electrolytic cell understanding and led to improved test scores.

Along with more practice using the algorithm for deciding electrode products, the results indicate that future instruction should place more emphasis on the half-reactions involving water. In particular, students should be shown how the two half-reactions involving the oxidation and reduction of water combine to yield the reaction for the decomposition of water into hydrogen and oxygen gas. This would include a discussion 
about relative molar amounts of gaseous products produced in this reaction and also stating observations that could be made due to the changes incurred during the electrolysis such as, gas bubbles at the electrodes, color or $\mathrm{pH}$ changes in the electrolyte.

\section{Student Attitude Towards Electrochemistry}

The confidence of students in their understanding of electrochemistry was greater among the experimental group, as illustrated by the fact that when given a choice, eight of the nine (89\%) students who took the higher-level test chose to answer the electrochemistry-related external exam question. This is compared to nine of sixteen (56\%) comparison group students making this same choice in the previous year, with awarded points ranging from $12 \%$ to $60 \%$. The details of the experimental students' test results were not available to the instructor at the time of this writing, but it is known with certainty that all eight students received passing grades from the IB organization on the overall test.

\section{Recurring Errors and Misconceptions}

Although the results of the study indicate some improved understanding of electrochemistry, there were still some common errors and misconceptions that need to be addressed during future instruction. These are discussed in the following, along with possible instructional methods that might be used to address them.

\section{Misconception about Electrolyte Conductivity}

The visualization provided by the computer simulation and physical model manipulation was intended, in part, to dispel the misconception that electricity is conducted through an electrolyte solution via free-electron movement. This particular 
misconception was also explicitly addressed during lecture and did not appear to exist in the short-term on the internal exam. However, after a time delay and in a stressful external exam situation, this particular misconception about conductivity recurred. Despite the fact that on the internal exam none of the comparison or experimental students referred to electricity conducted through an electrolyte solution via free-electron movement, two students in each group made reference to this mistaken belief on the external exam. In additional to using computer animation, researchers (e.g., Sanger \& Greenbowe, 2000) have had some success dispelling this persistent misconception using a series of demonstrations and discussions that challenge it and cause students to become dissatisfied until they must realign their thinking. In the future, it might be worth the time to try to dispel this particular misconception.

\section{Misunderstandings about Use of Equilibrium Arrows}

A second recurring error that worsened over time and grew more evident on the external exam was student use of equilibrium arrows when writing half-reactions for both types of cells. It is believed that this is not due to an actual misconception, but rather a lack of understanding of the relative nature of the standard reduction potentials table halfreactions and an over-reliance on copying from the table. To eliminate this error, several things might be done differently. First, when introducing a half-cell in the voltaic cell on day one, it should be emphasized that in a single, unconnected half-cell there is equilibrium between the solid electrode and the metal ion in solution. At this point, characteristics of the equilibrium state could be reviewed, one of which is that there is no change in the amount of reactant or product but an equal rate of change between them. 
The existence of a half-cell equilibrium was not previously stressed with either the experimental or comparison groups. Immediately following this, students could be directed to look at the table of standard reduction potentials and note the equilibrium symbols. (In the past, the standard reduction potentials table has not been referenced until day two during instruction on how to calculate cell voltage potential.)

Student manipulation of a voltaic cell model could then be used as a day one wrap-up activity as was done with the experimental group. It could be pointed out that in the voltaic cell with its two half-cells electrically connected, there is one electrode preferentially oxidized which means that electrode metal will "dissolve" into metal ions, and thus, lose mass. The other electrode experiences reduction which means that the metal ion from the solution will plate out onto the solid metal electrode and it will gain mass. Following the model manipulation, it could be clearly pointed out that when the two half-cells are electrically connected into a voltaic cell, there is no longer an equilibrium situation as there is a net movement of each respective type of particle in one direction. Therefore, it would be incorrect to show the half-reactions in a voltaic cell with equilibrium arrows.

Instead of starting out day two with introducing the formula for calculating cell potential, the instructor could begin with a quick review and a discussion of why the halfreactions in the table are written as equilibrium reactions. This is because they can run either way-depending on which half-cell the first half-cell is paired with. At this point, students could practice, given various pairs of two different half-cells and associated reactions, determining which half-reaction would run in the oxidation direction and 
which would run in the reduction (as shown on the table) direction. Students would write out each half-reaction in the appropriate direction with a one-way arrow. Adding this focused practice time should help insure that students do not include equilibrium arrows in half-reactions and that they understand the relative nature of the half-reactions found in the standard reduction table.

\section{Misconceptions about Calculating Cell Potential}

Another common misconception seen on both the internal and external exams for both the comparison and experimental groups was related to the incorrect use of the formula for calculating voltaic cell voltage. Following the explanation and practice writing half-reactions described in the previous section, on day two it would be appropriate to show the students how to calculate the cell potential by using the formula

$\mathrm{E}_{\text {cathode }}-\mathrm{E}_{\text {anode }}=\mathrm{E}_{\text {cell }}$. What helped most of the students in both the comparison and experimental groups to understand this formula was making an analogy to the previous study of the Hess' Law method for finding reaction heat and the principle of reversing the sign on the associated heat value when a reaction is reversed. Since it appeared to be effective, this approach should be continued.

A visual image of a waterfall overlaid on top of the standard reduction potentials table could provide some additional value here. As is normally done at this point of instruction, it would be explained that a positive $\mathrm{E}^{\circ}$ cell value indicates an operational voltaic cell with a spontaneous oxidation-reduction reaction and that the table voltage given for a half-cell is an intensive property analogous to the potential energy available in the height of a waterfall. Therefore, it is inappropriate to multiply the voltage by a factor 
when calculating the cell potential. (This is an important distinction because it is different than the procedure used in the Hess' Law heat method.) A vertical, double-headed arrow could be drawn between any two half-reactions on the waterfall and the different lengths

of the arrows would represent the maximum voltage potential available in that voltaic cell at standard conditions. This would help to eliminate two types of student errors observed in calculating cell potential. First, it would help students to remember that the potential for the cell is found by taking the difference between cathode and anode potentials. Secondly, it would help students to remember that the voltage of a spontaneous redox reaction in a voltaic cell is always positive as this allows electrons to flow, just as the potential energy of a waterfall must be positive in order for the water to flow. The verbal analogy of a waterfall has been employed in the past to help students remember that the voltage potential of a half-cell is intensive, but a more visual analogy has the potential to do even more.

\section{Misconceptions about the SHE}

The relative nature of the assigned half-cell voltages as compared to the chosen standard half-reaction of hydrogen reduction was discussed on day two with the experimental group. However, when students were asked to describe materials and conditions in the standard hydrogen electrode on the external exam, student scores were $50 \%$ (or less.) As was done with the experimental group, in the future, it should be explained that the hydrogen reduction half-reaction has been arbitrarily chosen as the basis of comparison for all the other half-reaction potentials and assigned zero voltage. Therefore, the standard electrode potential voltages shown in the standard reduction table 
are all relative to that of the standard hydrogen electrode (SHE) so it is impossible to directly measure the voltage potential of any single half-cell.

Again utilizing the visual image of a waterfall placed over the standard reduction table showing the hydrogen reduction half-reaction midway between the bottom and the top, it would be explained that the SHE is a half-cell that must have both hydrogen gas and $\mathrm{H}^{+}$ions available at standard conditions since it may be required to run in either direction depending on which standard half-cell it is paired with. Because the two forms of hydrogen are not solid, an inert platinum electrode is used. Using the visual image of the waterfall, with the hydrogen reduction half-reaction in the middle, may help to reiterate the fact that the designation of a standard electrode potential for a half-reaction is only accomplished relative to the SHE. Additionally, it may also help to emphasize that the SHE must contain both the oxidized and reduced versions of hydrogen at standard conditions as it may be needed to run in either direction depending upon whether the second half-cell reaction is located above or below it in the table.

During future instruction, students would then be asked to demonstrate their understanding by predicting the maximum and minimum cell potentials made possible by combining various half-reactions from the table. Also, students would be asked to suggest how a person might choose to design a nine-volt battery. Afterwards, students would pass around an actual nine-volt battery with its casing cut away to view the six, 1.5 volt batteries within. 


\section{Errors in Using the Algorithm for Electrolytic Cell Products}

The relatively low scores achieved by both groups on the internal and external exam questions regarding electrolytic cells indicate that more practice time is needed in using the algorithm for determining which products are made at each of the electrodes. To address this issue, on day nine, instead of administering the internal exam as in the past, electrolytic cell instruction would continue with the specific copper purification and electroplating applications required by the IB curriculum. The instructor could begin by drawing an electrolytic cell on the board containing two copper electrodes in copper II sulfate solution. Instead of being told what occurs, the instructor could instead ask the students to make two lists, one of any species (atoms/ions) in that cell capable of being oxidized and another list of any species capable of being reduced.

Referring to the standard reduction potentials table and employing the same algorithm used previously with the experimental group to correctly predict products of electrolysis in aqueous solutions, students would then be asked to predict what product will be made at each electrode. This new approach will provide two additional benefits: it will introduce the students to the algorithm earlier to allow for more practice time and allow students to analyze a simpler scenario before adding the complication of the possibility of water being oxidized or reduced. This same approach could be taken with an electroplating application using an electrolytic cell example containing a silver electrode combined with an iron electrode in a silver ion solution.

The students would then observe a computer simulation of the copper purification electrolytic cell and be asked to manipulate a physical model of a copper 
purification electrolytic cell. Employing the same visualization techniques used when teaching about voltaic cells should improve the electrolytic cell test results and make these results commensurate with those of the voltaic cell. Recall that the experimental group did observe a teacher-led demonstration of this electrolytic cell model but there was no opportunity for student manipulation of the model or a computer simulation.

On day ten, electrolytic cells with aqueous solutions would then be introduced. Using the same algorithm employed on the previous day and the example of copper electrodes in copper II sulfate but this time in aqueous solutions, a new analysis would be done. Students would list all possible oxidized species including water, and all possible reduced species including water. The two reactions showing water being oxidized and reduced would be highlighted by each student on his or her own standard reduction potentials table. The algorithm would again be used to correctly predict products made at each electrode. This was done in the past but in a very short time period and without any previous practice utilizing the algorithm. Following this introduction, the Flinn Scientific (2007) lab activity would then be introduced. This activity was completed by the experimental group, but only after the internal exam was graded and the instructor had noted the students' confusion about aqueous solution electrolytic cells.

\section{Problems Encountered and Limitations}

As mentioned earlier, there were many disruptions to the planned implementation of this experimental instructional plan. There were a total of ten interruptions during four weeks of class time spent on oxidation/reduction and seven of those were unplanned. The result was a lot of backtracking, quick reviews to bring everyone up to speed, and 
continual reworking of the plan to try to complete the electrochemistry topic within the planned time period. It has always been challenging to complete the prescribed IB higherlevel chemistry curriculum within the two years of instruction time allotted. There is little flexibility for additional activities without risking the students' overall performance on the IB external exam. More instruction time, especially spent with electrolytic cells, would no doubt improve test scores but it must be very efficient to be realistic.

\section{Summary}

Visualization practice in the form of model manipulation and computer simulation did appear to improve student understanding of electrochemistry as evidenced by the fact that test results for voltaic cell questions, to which these instructional techniques were related, were markedly better for students in the experimental group than for students in the comparison group who did not engage in such activities.. The effects appear to be more obvious in the short-term, however, since the internal exam completed immediately after instruction yielded stronger test scores than those seen on the external exam taken after a three-month delay.

Explicitly addressing common electrochemistry misconceptions in a lecture format also seemed to work well to prevent these misconceptions from appearing in the short-term, as on the internal exam. But particularly entrenched misconceptions, such as the belief that free-electron movement is necessary in order to conduct electricity, also reappeared after a delay as seen on the external exam.

Using a specific algorithm for determining the products of an electrolytic cell containing an aqueous electrolyte appeared to help all of the experimental group students 
to consider the possibility of water being oxidized or reduced, but did not necessarily result in students correctly predicting the products at each electrode. Test results indicate that because of the complexity of the process, more practice time is needed for learning to use this algorithm.

The changes made to electrochemistry instruction strategies as part of this project did result in an increase in the percentage of students who chose to answer an optional free-response question regarding this topic on the IB external exam, indicating increased student confidence in answering electrochemistry questions.

With small IB class sizes — eighteen students last year and thirteen this year - it is difficult to say with certainty that the instructional changes were the cause of any improvements in student understanding. In my experience, the experimental students were a particularly cohesive group with good problem-solving skills, many of who were also concurrently studying higher-level IB math. This could provide an alternative explanation for any documented test score improvements. However, given that the instructional modifications undertaken apparently caused no obvious decline in test scores, I plan to repeat the instructional approach taken last year with the upcoming class, with the modifications described above. I also plan to invest two additional class periods on the subject of electrolytic cells (days 9 and 10 above) prior to administering the internal exam. It should be also noted that there is still an unaddressed opportunity to improve student test scores and electrochemistry understanding by focusing further on the IB objective that was mentioned in chapter 4; 19.2.2 Determine the relative amounts of the products formed during electrolysis. 


\section{References}

Acar, B. \& Tarhan, L. (2006). Effect of cooperative learning strategies on students' understanding of concepts in electrochemistry. International Journal of Science and Mathematics Education, 5, 349-373.

Brown, T. L., LeMay, E. H., \& Bursten, B. E. (2006). Chemistry: The central science. 10th ed. Upper Saddle River, NJ: Pearson Prentice Hall.

Butts, B. \& Smith, R. (1987). What do students perceive as difficult in H.S.C. chemistry? Australian Science Teachers Journal, 32, 45-51.

Ceyhun, I. \& Karagolge, Z. (2005). Chemistry students' misconceptions in electrochemistry. Australian Journal of Education Chemistry, 65, 24-28.

Chromium Plating Metal (n.d.) Retrieved on 6/27/11 at http://cwx.prenhall.com/petrucci/medialib/media_portfolio/text_images/078_Elect roplating.MOV.

Demonstration of a Voltaic Cell (n.d.). Retrieved on 6/27/11 at http://www.blackgold.ab.ca/ict/Division4/science/Div.\%204/Voltaic\%20Cells/Vo ltaic.htm.

DiStasio, J. (1995). A Homework Booklet: Chemistry. Grand Rapids, MI: Instructional Fair Inc.

Electrolytic Cell (n.d.). Retrieved on 6/27/11 at http://www.chem.iastate.edu/group/Greenbowe/sections/projectfolder/flashfiles/el ectroChem/electrolysis 10.html.

Finley, F. N. Stewart, J., \& Yarroch, W. L. (1982). Teachers' perceptions of important and difficult science content.Science Education, 66, 531-538.

Flinn Scientific (2007). Producing Metals with Electricity. Publication No. 6877. Batavia, IL; Flinn Scientific Inc.

Garnett, P.J. \& Treagust, D.F. (1992). Conceptual difficulties experienced by senior high school students of electrochemistry: Electrochemical (galvanic) and electrolytic cells. Journal of Research in Science Teaching, 29, 1079-1099.

Howe, A. C. \& Durr, B. (1982). Using concrete materials and peer interaction to enhance learning in chemistry. Journal of Research in Science Teaching, 19, 225-232. 
Huddle, P. A., White, M. D., \& Rogers, F. (2000). Using a teaching model to correct known misconceptions in electrochemistry. Journal of Chemical Education, 77, 104-110.

International Baccalaureate Organization (IBO). (2007). IBO Diploma Programme Chemistry Guide; Cardiff, Wales, United Kingdom: IBO.

Nakhleh, M. B. (1993). Are our students conceptual thinkers or algorithmic problem solvers? Journal of Chemical Education, 70, 52-55.

Niaz, M. (2002). Facilitating conceptual change in students' understanding of electrochemistry. International Journal of Science Education, 24, 425-439.

Ogude, A. N. \& Bradley, J. D. (1994). Ionic conduction and electrical neutrality in operating electrochemical cells. Journal of Chemical Education, 71, 29-34.

Ogude, A. N. \& Bradley, J. D. (1996) Electrode processes and aspects relating to cell emf, current, and cell components in operating electrochemical cells. Journal of Chemical Education, 73, 1145-1149.

Ozkaya, A. R. (2002). Conceptual difficulties experienced by prospective teachers in electrochemistry: Half-cell potential, cell potential, and chemical and electrochemical equilibrium in galvanic cells. Journal of Chemical Education, 79, 735-738.

Ozkaya, A. R., Uce, M., Saricayir, H., \& Sahin, M. (2006). Effectiveness of a conceptual change-oriented teaching strategy to improve students' understanding of galvanic cells. Journal of Chemical Education, 83, 1719-1723.

Park, O-C. \& Hopkins, R. (1993). Instructional conditions for using dynamic visual displays: A review. Instructional Science, 21, 427-449.

Sanger, M. J. \& Greenbowe, T. J. (1997a). Common misconceptions in electrochemistry: Galvanic, electrolytic, and concentration cells. Journal of Research in Science Teaching, 34, 377-398.

Sanger, M. J. \& Greenbowe, T. J. (1997b). Students' misconceptions in electrochemistry: Current flow in electrolyte solutions and the salt bridge. Journal of Chemical Education, 74, 819-823.

Sanger, M. J. \& Greenbowe, T. J. (1999). An analysis of college chemistry textbooks as sources of misconceptions and errors in electrochemistry. Journal of Chemical Education, 76, 853-860. 
Sanger, M. J. \& Greenbowe, T. J. (2000). Addressing student misconceptions concerning electron flow in aqueous solutions with instruction including computer animations and conceptual change strategies. International Journal of Science Education, 22, 521-537.

Schmidt, H., Marohn, A., \& Harrison, A.G. (2007). Factors that prevent learning in electrochemistry. Journal of Research in Science Teaching, 44, 258-283.

Thompson, J. \& Soyibo, K. (2002). Effects of lecture, teacher demonstrations, discussion and practical work on $10^{\text {th }}$ graders attitudes to chemistry and understanding of electrolysis. Research in Science and Technological Education, 20, 25-37. 


\section{Appendix A - IRB Documentation}

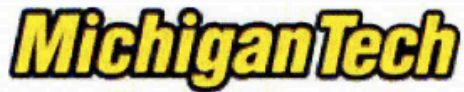 \\ Michigan Technological University}

\section{Office of Research Integrity and Compliance}

Lakeshore Center 1400 Townsend Drive

Houghton, Ml 49931

906.487 .2902

\section{MEMO}

TO: Dr. Shari Stockero, CLS

CC: Deb Corriveau, Notre Dame Academy

FROM: Joanne Polzien, Director Research Integrity and Compliance fo an me Palzen

DATE: December 17, 2010

\section{SUBJECT: Approval M0685}

Your application to use human subjects in research or classroom situations has been reviewed with the following determination:

Protocol \#: M0685

Protocol Title: "The Effects of Visualization Practice on Student Learning of Electrochemistry" Approved Dates: December 17, 2010 through December 16, 2011.

Approvals are granted for up to a one year period. You will need to request a continuation for each year of the project six weeks prior to the end date indicated above for each year of the project. The Office of Research Integrity and Compliance will make every effort to send the Principal Investigator annual reminders. However, the Principal Investigator is responsible for submitting annual Continuation Forms in advance of the expiration date for the project. It is very important that these expiration dates are not missed. Failure to submit annual review materials on time will result in the termination of this protocol.

This approval applies only for this project, and only under the conditions and procedures described in the application; if any changes are made in the protocol or conditions set forth in the application, the principal investigator must obtain a separate approval before these changes take place. The approved project will be subject to surveillance procedures requiring periodic review. This review will consist of consulting with the principal investigator and examining the appropriate project records.

Individual identification of human subjects in any publication is an invasion of privacy. Before beginning a project involving human subjects, and only if required, the principal investigator must obtain a properly executed informed consent from each subject and/or the person legally responsible for the subject. If a consent form has been reviewed and approved it has been attached with an official date stamp on it. Only copies of the official date stamped informed consent is to be distributed to participants relating to this project. If any changes or modifications are needed regarding this form, you must first submit the revised document for review and approval prior to use. The principal investigator must retain informed consent forms on file for at least three years after the end of the project. If a project involves a high level of risk, copies of the signed informed consent forms must be filed with the Human Subjects Committee; if this is the case, you will be notified.

This document is on file in the Office of Research Integrity and Compliance. If you have any questions, please contact me at 487-2902 or jpolzien@mtu.edu. 


\section{Dear Student and Parents/Guardian,}

I am working on a research project through Michigan Technological University as part of my Masters of Science in Applied Science Education. My research project is aimed at improved student understanding of electrochemistry, one of the most challenging topics in the International Baccalaureate higher-level chemistry curriculum.

I request permission for your child to participate in this project.

The study will consist of:

1. Student participation in class as normal; including discussions, physical model manipulation and computer simulations.

2. Giving me permission to use student work as part of the data for my study. This would include; tests administered during the electrochemistry unit, practice test questions completed in preparation for the IB exam and IB exam results on questions related to electrochemistry.

3. A survey to determine the number of students who might have chosen to answer optional questions regarding electrochemistry on the IB exam.

4. Possibly participating in a 1:1 teacher/student interview, if further clarification of my findings is required.

Only my advisor, Dr. Shari Stockero, and I will have access to information from your child. At the conclusion of the study, your child's individual results will be reported as a group result only; individual student work will not be identified by name. If a particular student is quoted or mentioned, they will be given an anonymous label, such as "Student A".

Participation in this study is voluntary. The decision whether or not to participate in the study is determined by the student and the parent/guardian. Your decision whether or not to participate in the project will not affect the normal services provided to your child. The student will still be responsible for the material taught during the unit. If the student agrees to participate, he or she is free to end participation at any time. You and your child are not waiving any legal claims, rights or remedies because of your participation in this research study.

Should you have any questions or desire for further information, please contact me by calling the school (920) 429-6165 or emailing me at DCorriveau@notredameacademy.com or contact Dr. Shari Stockero at (906) 487-1126 or stockero@mtu.edu. Please keep this letter. Complete and sign the second page, and have your child return it to me.

If you have any questions about your student's right as a research subject, you may contact the Michigan Technological University Institutional Review Board (IRB) by mail at 1400 Townsend Drive, Houghton, MI 49331, by phone at (906) 487-2902 or by email at jpolzien@mtu.edu.

Sincerely,

Deb Corriveau

Notre Dame Academy teacher
Dr. Shari Stockero

Assistant Professor

Michigan Technological University 


\section{Parental Consent}

\section{The Effects of Visualization Practice on Student Learning of Electrochemistry}

Please indicate whether or not you wish to allow your child to participate in this project by checking the statements below, signing your name and having your child return this page to me. Keep the letter for your record.

I grant permission for my child to participate in Deb Corriveau's study of The Effects Visualization Practice on Student Learning of Electrochemistry.

I do not grant permission for my child to participate in Deb Corriveau's study of The Effects Visualization Practice on Student Learning of Electrochemistry.

Signature of Parent/Guardian

Printed Name of Child
Printed Parent/Guardian Name

Date

Student Assent to Participate in Research

I have read and understand the terms defined in the letter to students and parent/guardians for Deb Corriveau's study of The Effects Visualization Practice on Student Learning of Electrochemistry. If I have questions, I understand that I can ask them at any time during the classroom unit or I can contact Mrs. Corriveau by emailing her at DCorriveau@NotreDameAcademy.com.

Please check one of the following, and return this page to Mrs. Corriveau. Again, keep the cover letter for your records.

I do agree to participate in Deb Corriveau's study of The Effects Visualization Practice on Student Learning of Electrochemistry.

I have read the letter and understand its terms and I agree to these terms.

I do not agree to participate in Deb Corriveau's study of The Effects Visualization Practice on Student Learning of Electrochemistry. I do not wish my class work or scores to be used in the study. 


\section{Appendix B - Common Student Misconceptions in Electrochemistry}

(Compiled from Garnett \& Treagust, 1992; Huddle, White, \& Rogers, 2000;Ogude \& Bradley, 1994; Ogude \& Bradley, 1996; Sanger \& Greenbowe, 1997a.)

Note: The wrong word or phrase is italicized in each misconceptions statement below.

In the voltaic cell: The plus and minus electrodes carry a measurable charge.

In all types of cells: Cathode is always the $(-)$ pole and anode always the $(+)$ pole.

The anode is always the half-cell drawn on the left side in an electrochemical cell diagram.

In voltaic/electrochemical cells, anions and cations move either until their concentration in both $1 / 2$ cells is equal or until one $1 / 2$ cell is strongly (-) and the other $1 / 2$ cell, strongly

$(+)$.

(SHE) Standard Hydrogen Electrode

The designation of the hydrogen half-cell as voltage as zero volts is not arbitrary but is somehow based on the chemistry of the $\mathrm{H}_{2}$ and $\mathrm{H}^{+}$.

A std half-cell is not necessary to measure a voltage of a given half-cell reaction.

\section{Half-cell Potentials}

Half-cell potentials are absolute in nature and can be used to predict the spontaneity of any half-cell.

Cell potentials are derived by adding individual reduction potentials.

The potential difference between two points is solely due to differences in the

concentrations of charges at the points.

i.e. There is a high e-concentration at the anode.

There is a low e-concentration at the cathode.

Electrons leave the anode where there is high concentration of e-s and move thru the external circuit to the cathode where there is a low concentration of $e-s$.

Half-cell potentials (assigned table reduction potential voltages) are not intensive properties.

\section{Current in Electrochemical cell}

Electric current always involves movement of e-s even in solution and in the salt bridge.

Electrons migrate thru solution from one electrode to another.

The movement of ions in solution does not constitute an electric current.

Electrons enter the electrolyte at the cathode, move thru the electrolyte and emerge at the anode.

A piece of copper wire or graphite can used to replace the salt bridge.

The salt bridge supplies electrons to complete the circuit.

The salt bridge assists the flow of current (via electrons) because positive ions in the bridge attract electrons from one half cell to the other half cell.

Electrons move through solution by being attracted from one ion to the other.

Electrons move through solution by attaching themselves to ions at the cathode and are carried by that ion to the anode.

Electrons enter the solution from the cathode, travel thru the solutions and the salt bridge and emerge at the anode to complete the circuit 
Anions in the salt bridge and the electrolyte transfer e-s from the cathode to the anode. Cations in the salt bridge and the electrolyte accept e-s and transfer them from the cathode to the anode.

Electrons can flow thru aqueous solutions without assistance from the ions.

Only negatively charged ions constitute a flow of current in the electrolyte and the salt bridge.

The anions and cations move until the concentration in both half-cells is equal.

Charge on anode and cathode in electrochemical cells.

The anode is $(-)$ charged and because of this it attracts cations. The cathode is $(+)$ charged and because of this it attracts anions.

The anode is positively charged because it has lost electrons. The cathode is (-) charged because it has gained e-s.

\section{Electrolytic cells}

During electrolysis, electric current produces ions (from the salt electrolyte.) Electrolysis - if identical electrode materials (e.g., graphite rods) are connected to the battery, the same rxns occurs at both electrodes.

Electrolysis- there is no way to predict which rxn occurs when 2 or more redox rxns are possible.

The polarity of the battery terminals of the applied voltage has no effect on the site of the anode and cathode.

No rxns will occur at the surface of inert electrodes (like graphite or platinum).

Processes (e.g., oxidation and reduction) at the anode and cathode are reversed in voltaic and electrolytic cells. In voltaic cells, oxidation occurs at the anode and reduction at the cathode, while in electrolytic cells oxidation occurs at the cathode and reduction at the anode.

Calculated cell potentials in electrolytic cells can be positive. (remember, the whole point is to push non-spontaneous rxns to occur!) The predicted e.m.f. for an electrolytic cell may be positive.

Inert electrodes can be oxidized or reduced.

\section{Predicting electrolysis products}

Water does not react during electrolysis of aqueous solutions. When predicting electrolytic cell rxns, the oxidation and reduction half equations from the std reduction potential tables are reversed prior to combining them.

The direction of the applied voltage (battery terminal arrangement) has no effect on the site of the anode and cathode.

In an ordered list of reduction potentials, the species with the most positive $\mathrm{E}$ value is the anode. 
Appendix C - Physical Models of Cells
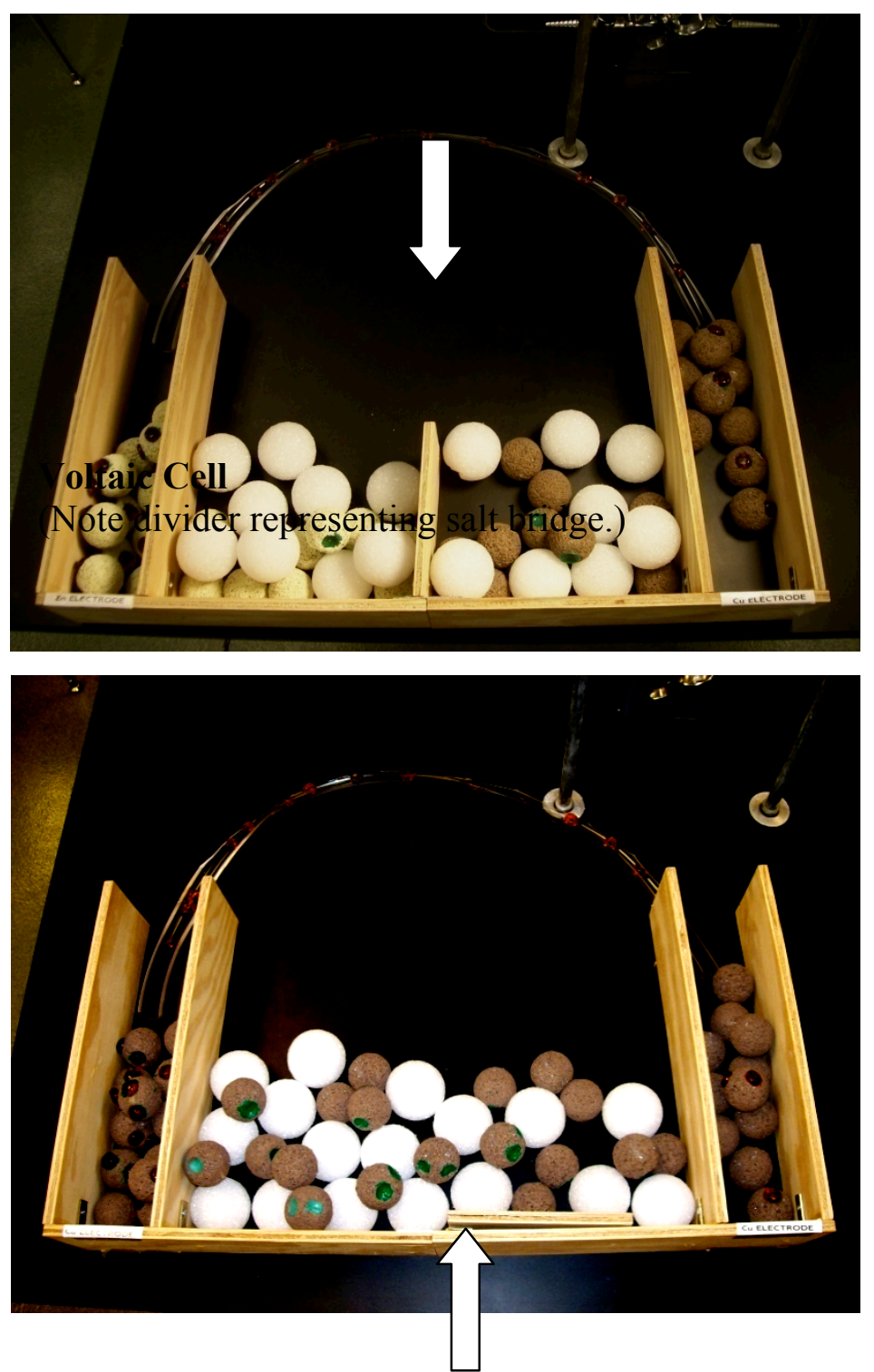

Electrolytic Cell: (Note divider has been lowered to allow for one electrolyte compartment.) 


\section{Appendix D}

\section{Interactive Lab \\ Investigating Voltaic Cells}

Joltaic cells used in research consist of two half-cells, each with an electrode and an electrolyte, separated by a porous boundary. The purpose of this investigation is to demonstrate the design and operation of a voltaic cell used in scientific research.

In the Google search engine, type in "demonstration of a voltaic cell." Click on the link with the following address listed with it www.blackgold.ab.ca/ICT/Division4/Science/Div.\%204/Voltaic\%20Cells/Voltaic.htm

Purpose: To investigate the design and operation of a voltaic cell using different electrodes and electrolytes.

Click on the "Voltaic Cell Animation" and view the properties and motion of a voltaic cell. Answer the following questions from the animation.

1. What direction do electrons flow?

2. What is occurring at the cathode?

3. What is occurring at the anode?

4. What is the purpose of a salt bridge?

\section{Procedure:}

1. Set up each of the following simulations to represent a voltaic cell. Do one at a time.

\begin{tabular}{|c|c|c|c|}
\hline Anode & Solution (1M) & Cathode & Solution (1M) \\
\hline $1 . \mathrm{Cu}$ & $\mathrm{Cu}\left(\mathrm{NO}_{3}\right)_{2}$ & $\mathrm{Ag}$ & $\mathrm{AgNO}$ \\
\hline $2 . \mathrm{Zn}$ & $\mathrm{Zn}\left(\mathrm{NO}_{3}\right)_{2}$ & $\mathrm{Cu}$ & $\mathrm{Cu}\left(\mathrm{NO}_{3}\right)_{2}$ \\
\hline $3 . \mathrm{Zn}$ & $\mathrm{Zn}\left(\mathrm{NO}_{3}\right)_{2}$ & $\mathrm{Ag}$ & $\mathrm{AgNO}_{3}$ \\
\hline
\end{tabular}

a. Write the complete reaction and the half reactions for each of the voltaic cells given above.

(1)

(2)

(3) 
2. After a minute or two has passed, the words "Molecular Level Reaction" will appear on your screen. Click on it to view the electrodes at a molecular level to help you better understand the halfreactions.

3. Use the voltmeter to test each of the combinations to determine which electrode is positive or negative. Remember to use the refresh button between each simulation by clicking on the "ON/OFF" button.

4. Record voltages produced for each cell combination. Potentials must be positive. If the voltmeter has a negative reading, the electrodes must be switched.

bservations

1. Fill in the cell potential for each of the electrodes and electrolytes used in the voltaic cell.

\begin{tabular}{c|c|c|c|c}
\hline Anode & Solution (1M) & Cathode & Solution (1M) & Cell Potential \\
\hline $1 . \mathrm{Cu}$ & $\mathrm{Cu}\left(\mathrm{NO}_{3}\right)_{2}$ & $\mathrm{Ag}$ & $\mathrm{AgNO}_{3}$ & \\
\hline $2 . \mathrm{Zn}$ & $\mathrm{Zn}\left(\mathrm{NO}_{3}\right)_{2}$ & $\mathrm{Cu}$ & $\mathrm{Cu}\left(\mathrm{NO}_{3}\right)_{2}$ & \\
\hline $3 . \mathrm{Zn}$ & $\mathrm{Zn}\left(\mathrm{NO}_{3}\right)_{2}$ & $\mathrm{Ag}$ & $\mathrm{AgNO}_{3}$ & \\
\hline
\end{tabular}

2. Label the following diagrams to show the three voltaic cells. Identify the electrodes, electrolytes, electron flow, and direction of the ion movement for each diagram. Label the cathode, anode, and write the half-reactions and the net cell reaction for each.
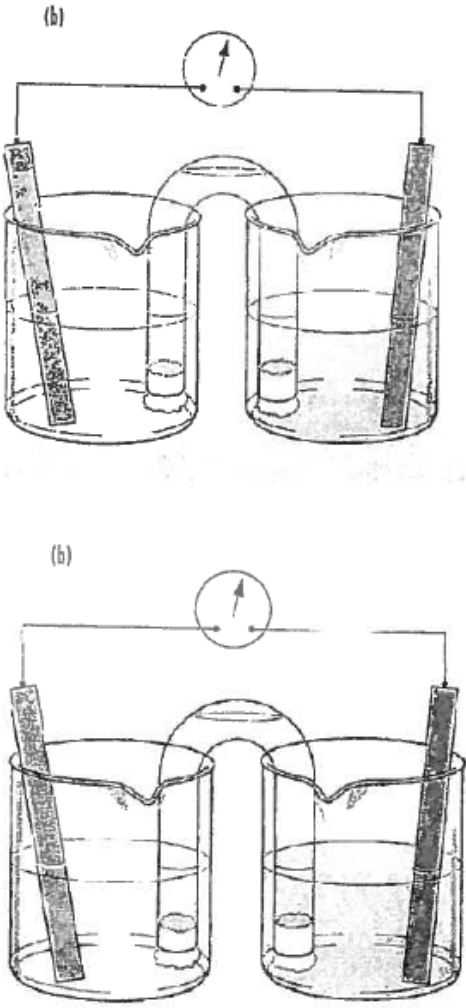


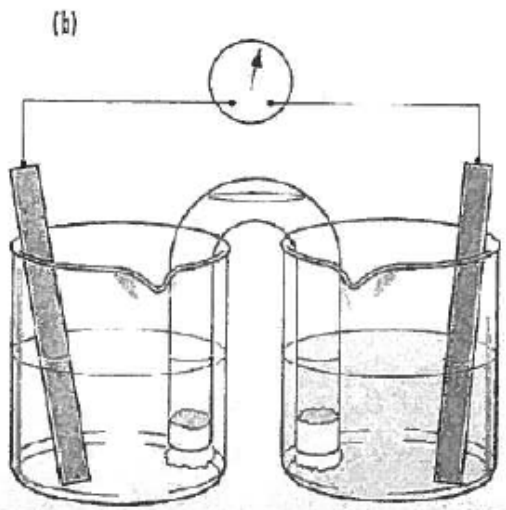

Experiment with different concentrations. Which gives you the best reading on the voltmeter? Wh: do you think that specific concentration gave you the highest reading? 


\section{Appendix E -Laboratory Instructions for Building a Voltaic Cell}

Instructions for Designing Your own Experiment: Investigating Effects of a Change on Voltaic Cell Voltage

Materials: high resistance voltmeter, two wires with alligator clips, porous cup, voltaic cell container,

$\mathrm{Cu}$ and $\mathrm{Zn}$ metal electrodes, 20.0mL 1.0 $\mathrm{M} \mathrm{CuSO}_{4}$ solution and $15.0 \mathrm{~mL}^{1.0} \mathrm{M} \mathrm{ZnSO}_{4}$ solution.

Obtain a porous cup and place it in a $400 \mathrm{~mL}$ beaker of distilled water for 5 minutes to wet the cup.

Be gentle with the cup as it is fragile!

Add $15-20 \mathrm{~mL}$ of $1 \mathrm{M} \mathrm{CuSO}_{4}$ to the voltaic cell container. Obtain a strip of copper metal and clean it with steel wool. Place the copper strip in the container with the $\mathrm{CuSO}_{4}$ solution to serve as an electrode.

Remove the porous cup from the distilled water and pour $15 \mathrm{~mL}$ of $1 \mathrm{M} \mathrm{ZnSO}_{4}$ solution into the porous cup. Obtain a strip of $\mathrm{Zn}$ metal and clean it with steel wool. Place the zinc strip into the $\mathrm{Zn}^{+2}$ solution in the porous cup. Connect one alligator clip lead of the voltmeter to the copper strip and connect the other lead of the voltmeter to the $\mathrm{Zn}$ strip. If you do not get a positive voltage reading, reverse your alligator clip leads.

Place the porous cup containing the $\mathrm{Zn} \mathrm{I} \mathrm{Zn}{ }^{+2}$ half cell into the beaker containing the $\mathrm{Cu} \mathrm{I}$ $\mathrm{Cu}^{+2}$ half cell.

Allow the cell to stand until the voltage reading on the voltmeter has stabilized. Record the highest voltage obtained. $\mathrm{V}$

Compare this voltage to the book value for the $\mathrm{E}^{\circ}$ cell $=1.10 \mathrm{~V}$

Now think about investigating something about this cell that would potentially cause voltage to be different. What would you have to control in order to avoid "muddying the waters"?

Do you have a hypothesis about how your change would affect the cell voltage? Be prepared to explain your reasoning. 


\section{Appendix F - Internal Exam}

IB HL Chemistry Redox chapter 9 Test $\quad$ (50 pts)

1. Consider the following spontaneous reactions.

$$
\begin{aligned}
& \mathrm{Fe}(\mathrm{s})+\mathrm{Cu}^{+2}(\mathrm{aq}) \rightarrow \mathrm{Fe}^{+2}(\mathrm{aq})+\mathrm{Cu}(\mathrm{s}) \\
& \mathrm{Cu}(\mathrm{s})+2 \mathrm{Ag}^{+}(\mathrm{aq}) \rightarrow \mathrm{Cu}^{+2}(\mathrm{aq})+2 \mathrm{Ag}(\mathrm{s}) \\
& \mathrm{Zn}(\mathrm{s})+\mathrm{Fe}^{+2}(\mathrm{aq}) \rightarrow \mathrm{Zn}^{+2}(\mathrm{aq})+\mathrm{Fe}(\mathrm{s})
\end{aligned}
$$

Which is the correct combination of strongest oxidizing agent and strongest reducing agent?

\begin{tabular}{|l|l|l|}
\hline & Strongest oxidizing agent & Strongest reducing agent \\
\hline$A$ & $\mathrm{Ag}(\mathrm{s})$ & $\mathrm{Zn}(\mathrm{s})$ \\
\hline$B$ & $\mathrm{Ag}^{+}(\mathrm{aq})$ & $\mathrm{Zn}(\mathrm{s})$ \\
\hline $\mathrm{C}$ & $\mathrm{Zn}^{+2}(\mathrm{aq})$ & $\mathrm{Ag}(\mathrm{s})$ \\
\hline$D$ & $\mathrm{Zn}(\mathrm{s})$ & $\mathrm{Ag}^{+}(\mathrm{aq})$ \\
\hline
\end{tabular}

2.Which statement is correct?

A. Spontaneous reactions produce electricity in an electrolytic cell.

B. Electricity is used to carry out non-spontaneous redox reactions in a voltaic cell.

C. Oxidation takes place at the negative electrode in a voltaic cell and the positive electrode in an electrolytic cell.

D. Oxidation takes place at the negative electrode in a voltaic cell and reduction takes place at the positive electrode in an electrolytic cell.

3. In the electrolysis of acidified water, if $8.4 \mathrm{~cm}^{3}$ of hydrogen gas is evolved, what volume of oxygen gas is evolved?

A. $4.2 \mathrm{~cm}^{3}$

B. $8.4 \mathrm{~cm}^{3}$

C. $12.6 \mathrm{~cm}^{3}$

D. $16.8 \mathrm{~cm}^{3}$

4. Why does the water have to be "acidified" in question \#3?

5. Dilute sulfuric acid is electrolyzed using inert electrodes. What product, and in what relative amount, is produced at each electrode?

\begin{tabular}{|l|l|l|}
\hline & Positive electrode & Negative electrode \\
\hline A. & $1 \mathrm{~mol} \mathrm{H}_{2}$ & $2 \mathrm{~mol} \mathrm{O}_{2}$ \\
\hline B. & $1 \mathrm{~mol} \mathrm{O}_{2}$ & $2 \mathrm{~mol} \mathrm{H}_{2}$ \\
\hline C. & $2 \mathrm{~mol} \mathrm{H}_{2}$ & $1 \mathrm{~mol} \mathrm{O}_{2}$ \\
\hline D & $2 \mathrm{~mol} \mathrm{O}_{2}$ & $1 \mathrm{~mol} \mathrm{H}_{2}$ \\
\hline
\end{tabular}


6. Which factors affect the amount of metal formed during electrolysis?

I. Charge on the metal ion

II. Current

III. Time
A. I and II only
B. I and III only
C. II and III only
D. I, II and III

7. Assign oxidation states to the following species: ( $5 \mathrm{pts})$.
Sulfur in $\mathrm{Na}_{2} \mathrm{SO}_{3}$
Nitrogen in $\mathrm{NO}_{3}^{-1}$
Chromium in $\mathrm{CrO}_{4}^{-2}$
Manganese in $\mathrm{MnO}_{2}$
Carbon in $\mathrm{CO}_{2}$

8. What is the coefficient for $\mathrm{H}^{+}(\mathrm{aq})$ when this redox equation is balanced using whole numbers?

$$
\mathrm{Cr}_{2} \mathrm{O}_{7}^{-2}(\mathrm{aq})+\mathrm{Cl}^{-}(\mathrm{aq})+\mathrm{H}^{+}(\mathrm{aq}) \rightarrow \mathrm{Cr}^{+3}(\mathrm{aq})+\mathrm{Cl}_{2}(\mathrm{~g})+\mathrm{H}_{2} \mathrm{O}(\mathrm{l})
$$
A. 7
B. 2
C. 14
D. 1

9.Tin(II) ion can be oxidized to tin IV ions by acidified potassium permanganate (VII) solution according to the following unbalanced reaction.

$$
-\mathrm{Sn}^{+2}+\ldots \mathrm{MnO}_{4}^{-1}+\ldots \mathrm{H}^{+} \rightarrow \mathrm{Sn}^{+4}+\ldots \mathrm{Mn}^{+2}+{ }^{-} \mathrm{H}_{2} \mathrm{O}
$$

Identify the oxidizing agent and the reducing agent. ( 2 pts)

Oxidizing agent:

Reducing agent:

Balance the equation above using half reactions.( 6 pts) 
10. The following diagram shows a voltaic cell. ( $13 \mathrm{pts}$ )

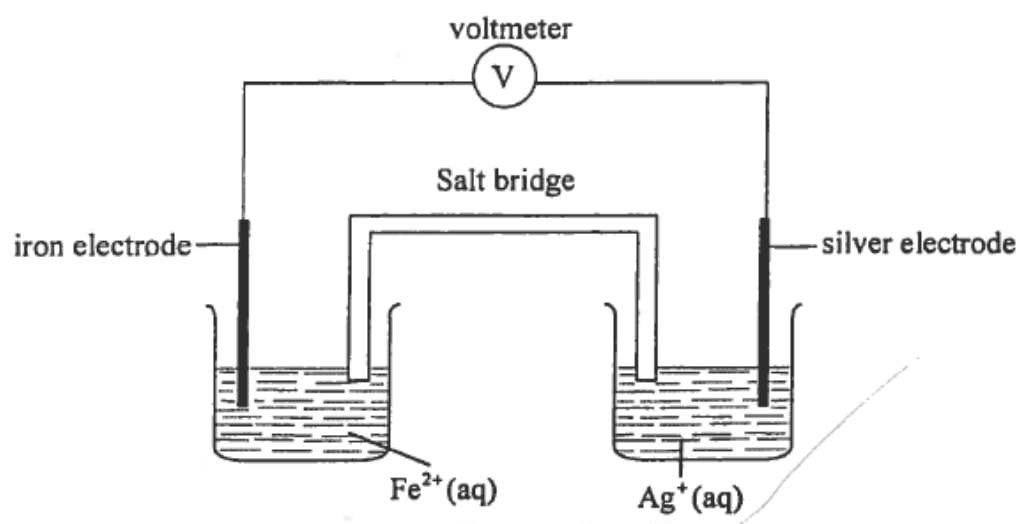

a)State an equation ( including states) to represent the spontaneous reaction occurring in the cell. ( 5 pts)

b) Under what conditions are standard electrode potential measured? ( 3 pts)

c) Use the standard electrode potential chart to calculate the standard cell potential for the spontaneous reaction above.( 2 pts)

d) Draw arrows on the above diagram to indicate the direction of electron flow.

e)Draw arrows to represent the direction of flow of cations and anions through the salt bridge. 
11. Electrolysis of an aqueous solution of copper II sulfate, $\mathrm{CuSO}_{4}$, can be carried out using platinum electrodes.

a. State an equation for the half reaction occurring at the positive electrode (anode) and one observation that could be made as a result.( 2 pts)

b. State an equation for the half reaction occurring at the negative electrode (cathode) and one observation that could be made as a result.( 2 pts)

c. Describe two change or observations in the electrolyte as a result of these two half reactions. ( 2 pts)

d. Determine the relative amount, in moles, of products formed at each electrode.(2 pts)

e. What products would be formed at the anode and cathode if the electrolyte was changed to concentrated $\mathrm{CuCl}_{2}(\mathrm{aq})$ ? ( 2 pts)

$f$. The same process as described in part (a) is carried out using copper electrodes instead of the platinum electrodes. Describe the changes or observations that take place at both the electrodes and in the electrolyte.( 5 pts)

What would be the purpose of such an electrolytic cell?

g. Identify two factors that affect the quantity of copper produced during the electrolysis of an aqueous copper II sulfate solution.( 2 pts) 


\section{Standard electrode potentials}

\begin{tabular}{|c|c|c|}
\hline Oxidized species & Reduced species & $E^{\bullet} / \mathrm{V}$ \\
\hline $\mathrm{Li}^{+}(\mathrm{aq})+\mathrm{e}^{-}$ & $\Longrightarrow \quad \mathrm{Li}(\mathrm{s})$ & -3.04 \\
\hline $\mathrm{K}^{+}(\mathrm{aq})+\mathrm{e}^{-}$ & $=\mathrm{K}(\mathrm{s})$ & -2.93 \\
\hline $\mathrm{Ca}^{2+}(\mathrm{aq})+2 \mathrm{e}^{-}$ & $\Longrightarrow \mathrm{Ca}(\mathrm{s})$ & -2.87 \\
\hline $\mathrm{Na}^{+}(\mathrm{aq})+\mathrm{e}^{-}$ & $\Longrightarrow$ & -2.71 \\
\hline $\mathrm{Mg}^{2+}(\mathrm{aq})+2 \mathrm{e}^{-}$ & $\Longrightarrow \mathrm{Mg}(\mathrm{s})$ & -2.37 \\
\hline $\mathrm{Al}^{3+}(\mathrm{aq})+3 \mathrm{e}^{-}$ & $\Longrightarrow \quad \mathrm{Al}(\mathrm{s})$ & -1.66 \\
\hline $\mathrm{Mn}^{2+}(\mathrm{aq})+2 \mathrm{e}^{-}$ & $\operatorname{Mn}(s)$ & -1.19 \\
\hline $\mathrm{H}_{2} \mathrm{O}(1)+\mathrm{e}^{-}$ & $=1 / 2 \mathrm{H}_{2}(\mathrm{~g})+\mathrm{OH}^{-}(\mathrm{aq})$ & -0.83 \\
\hline $\mathrm{Zn}^{2+}(\mathrm{aq})+2 \mathrm{e}^{-}$ & $\mathrm{Zn}(\mathrm{s})$ & -0.76 \\
\hline $\mathrm{Fe}^{2+}(\mathrm{aq})+2 \mathrm{e}^{-}$ & $\Longrightarrow$ & -0.45 \\
\hline $\mathrm{Ni}^{2+}(\mathrm{aq})+2 \mathrm{e}^{-}$ & $\Longrightarrow$ & -0.26 \\
\hline $\mathrm{Sn}^{2+}(\mathrm{aq})+2 \mathrm{e}^{-}$ & $\operatorname{Sn}(s)$ & -0.14 \\
\hline $\mathrm{Pb}^{2+}(\mathrm{aq})+2 \mathrm{e}^{-}$ & $\mathrm{Pb}(\mathrm{s})$ & -0.13 \\
\hline $\mathrm{H}^{+}(\mathrm{aq})+\mathrm{e}^{-}$ & $1 / 2 \mathrm{H}_{2}(\mathrm{~g})$ & 0.00 \\
\hline $\mathrm{Cu}^{2+}(\mathrm{aq})+\mathrm{e}^{-}$ & $\mathrm{Cu}^{+}(\mathrm{aq})$ & +0.15 \\
\hline $\mathrm{SO}_{4}{ }^{2-}(\mathrm{aq})+4 \mathrm{H}^{+}(\mathrm{aq})+2 \mathrm{e}^{-}$ & $\mathrm{H}_{2} \mathrm{SO}_{3}(\mathrm{aq})+\mathrm{H}_{2} \mathrm{O}(\mathrm{l})$ & +0.17 \\
\hline $\mathrm{Cu}^{2+}(\mathrm{aq})+2 \mathrm{e}^{-}$ & $\mathrm{Cu}(\mathrm{s})$ & +0.34 \\
\hline $1 / 2 \mathrm{O}_{2}(\mathrm{~g})+\mathrm{H}_{2} \mathrm{O}(\mathrm{l})+2 \mathrm{e}^{-}$ & $2 \mathrm{OH}^{-}(\mathrm{aq})$ & +0.40 \\
\hline $\mathrm{Cu}^{+}(\mathrm{aq})+\mathrm{e}^{-}$ & $\mathrm{Cu}(\mathrm{s})$ & +0.52 \\
\hline $1 / 2 I_{2}(s)+e^{-}$ & $\mathrm{I}^{-}$(aq) & +0.54 \\
\hline $\mathrm{Fe}^{3+}(\mathrm{aq})+\mathrm{e}^{-}$ & $\mathrm{Fe}^{2+}(\mathrm{aq})$ & +0.77 \\
\hline $\mathrm{Ag}^{+}(\mathrm{aq})+\mathrm{e}^{-}$ & $\mathrm{Ag}(\mathrm{s})$ & +0.80 \\
\hline $1 / 2 \mathrm{Br}_{2}(1)+\mathrm{e}^{-}$ & $\mathrm{Br}^{-}(\mathrm{aq})$ & +1.07 \\
\hline $1 / 2 \mathrm{O}_{2}(\mathrm{~g})+2 \mathrm{H}^{+}(\mathrm{aq})+2 \mathrm{e}^{-}$ & $\mathrm{H}_{2} \mathrm{O}(1)$ & +1.23 \\
\hline $\mathrm{Cr}_{2} \mathrm{O}_{7}{ }^{2-}(\mathrm{aq})+14 \mathrm{H}^{+}(\mathrm{aq})+6 \mathrm{e}^{-}$ & $2 \mathrm{Cr}^{3+}(\mathrm{aq})+7 \mathrm{H}_{2} \mathrm{O}(\mathrm{l})$ & +1.33 \\
\hline $1 / 2 \mathrm{Cl}_{2}(\mathrm{~g})+\mathrm{e}^{-}$ & $\mathrm{Cl}^{-}(\mathrm{aq})$ & +1.36 \\
\hline $\mathrm{MnO}_{4}^{-}(\mathrm{aq})+8 \mathrm{H}^{+}(\mathrm{aq})+5 \mathrm{e}^{-}$ & $\mathrm{Mn}^{2+}(\mathrm{aq})+4 \mathrm{H}_{2} \mathrm{O}(\mathrm{l})$ & +1.51 \\
\hline $1 / 2 F_{2}(g)+e^{-}$ & $F^{-}(a q)$ & +2.87 \\
\hline
\end{tabular}




\section{Appendix G - External Exam Question and Rubric}

6. (a) (i) Draw an annotated diagram of a voltaic cell composed of a magnesium electrode in $1.0 \mathrm{~mol} \mathrm{dm}^{-3}$ magnesium nitrate solution and a silver electrode in $1.0 \mathrm{~mol} \mathrm{dm}^{-3}$ silver nitrate solution. Indicate the direction of electron flow on your diagram.

(ii) Deduce half-equations for the oxidation and reduction reactions.

(iii) Using Table 14 of the Data Booklet, calculate the cell potential for this cell.

(b) The standard electrode potentials for three other electrode systems are given below.

\begin{tabular}{|l|c|}
\hline & $E^{\ominus} / \mathbf{V}$ \\
\hline $\mathrm{MnO}_{4}{ }^{-}(\mathrm{aq})+8 \mathrm{H}^{+}(\mathrm{aq})+5 \mathrm{e}^{-} \rightleftharpoons \mathrm{Mn}^{2+}(\mathrm{aq})+4 \mathrm{H}_{2} \mathrm{O}(\mathrm{l})$ & +1.51 \\
\hline $\mathrm{Fe}^{3+}(\mathrm{aq})+\mathrm{e}^{-} \rightleftharpoons \mathrm{Fe}^{2+}(\mathrm{aq})$ & +0.77 \\
\hline $\mathrm{Cd}^{2+}(\mathrm{aq})+2 \mathrm{e}^{-} \rightleftharpoons \mathrm{Cd}(\mathrm{s})$ & -0.40 \\
\hline
\end{tabular}

(i) Identify which species in the table above is the best reducing agent.

(ii) Deduce the equation for the overall reaction with the greatest cell potential.

(c) These values were obtained using a standard hydrogen electrode. Describe the materials and conditions used in the standard hydrogen electrode. (A suitably labelled diagram is acceptable).

(d) (i) Solid sodium chloride does not conduct electricity but molten sodium chloride does. Explain this difference.

(ii) Outline what happens in an electrolytic cell during the electrolysis of molten sodium chloride using inert electrodes. Deduce equations for the reactions occurring at each electrode.

(iii) Two electrolytic cells are connected in series as shown in the diagram below. In one there is molten magnesium chloride and in the other, dilute sodium hydroxide solution. Both cells have inert electrodes. If $12.16 \mathrm{~g}$ of magnesium is produced in the first cell, deduce the identity and mass of products produced at the positive and negative electrodes in the second cell.

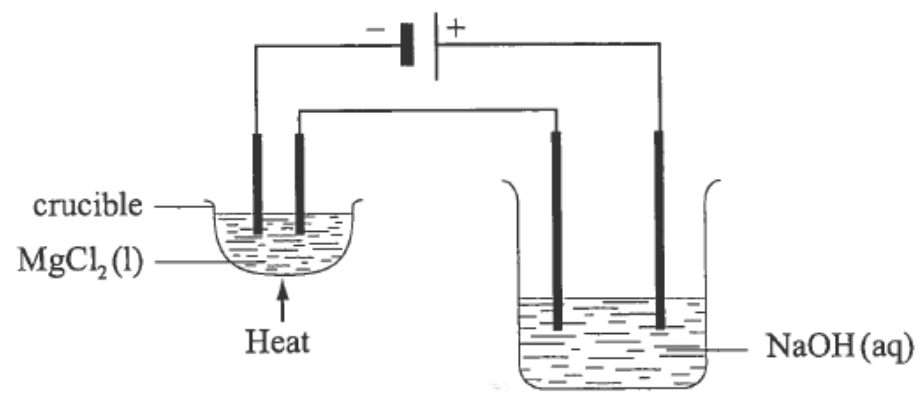


6. (a) (i)

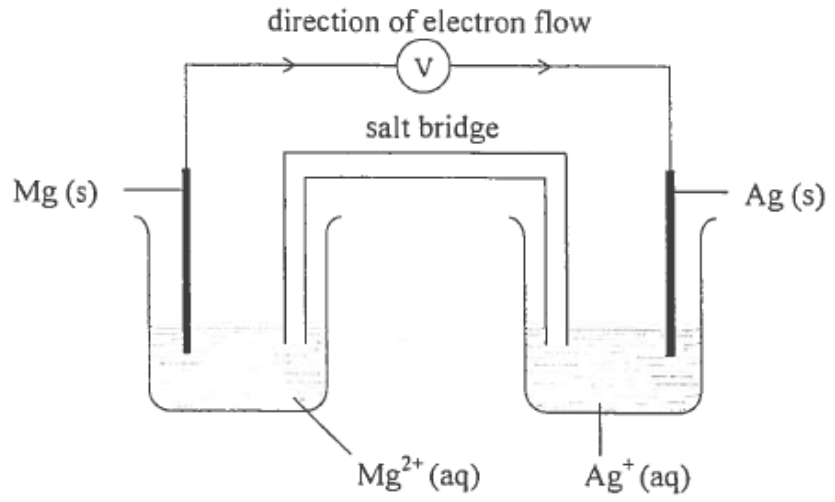

correctly labelled electrodes and solutions;

labelled salt bridge;

voltmeter;

Allow bulb or ammeter.

direction of electron flow;

(ii) Oxidation:

$\mathrm{Mg}(\mathrm{s}) \rightarrow \mathrm{Mg}^{2+}(\mathrm{aq})+2 \mathrm{e}^{-}$;

Reduction:

$\mathrm{Ag}^{+}(\mathrm{aq})+\mathrm{e}^{-} \rightarrow \mathrm{Ag}(\mathrm{s})$

Ignore state symbols.

Award [1 max] if equations not labelled reduction or oxidation or labelled the wrong way round.

Allow e instead of $e^{-}$.

Penalize equilibrium sign or reversible arrows once only in parts (a) (ii) and (d) (ii).

(iii) $+0.80-(-2.37)=3.17 \mathrm{~V}$

correct data;

answer with unit;

Award [1] for $-3.17 \mathrm{~V}$ or correct working of wrong values.

(b) (i) $\mathrm{Cd} / \mathrm{Cd}(\mathrm{s})$;

Do not allow $\mathrm{Cd}^{2+}$.

(ii) $5 \mathrm{Cd}(\mathrm{s})+2 \mathrm{MnO}_{4}^{-}(\mathrm{aq})+16 \mathrm{H}^{+}(\mathrm{aq}) \rightarrow 5 \mathrm{Cd}^{2+}(\mathrm{aq})+2 \mathrm{Mn}^{2+}(\mathrm{aq})+8 \mathrm{H}_{2} \mathrm{O}$ (l)

correct reactants and products;

correct balancing of this equation;

Ignore state symbols. 
(c) Accept suitable diagram with the following indicated:

Pt electrode;

$\left[\mathrm{H}^{+}(\mathrm{aq})\right]=1 \mathrm{~mol} \mathrm{dm}-3 / 0.5 \mathrm{~mol} \mathrm{dm}^{-3} \mathrm{H}_{2} \mathrm{SO}_{4}$;

$\mathrm{H}_{2}$ gas;

at $1 \mathrm{~atm} / 1.01 \times 10^{5} \mathrm{~Pa}$;

Do not award mark for pressure if no hydrogen gas given.

$298 \mathrm{~K} / 25^{\circ} \mathrm{C}$;

$[4 \max ]$

(d) (i) sodium chloride crystals consist of 1ons a (rigid) lattice / ions cannot move (to electrodes) / OWTTE;

when melted ions free to move/ions)move when potential difference/voltage applied;

(ii) positive sodium ions $/ \mathrm{Na}^{+}$move to the negative electrode/cathode and negative chloride ions $/ \mathrm{Cl}^{-}$move to the positive electrode/anode;

electrons are released to positive electrode/anode by negative ions and accepted from negative electrode/cathode by positive ions / reduction occurs at the negative electrode/cathode and oxidation occurs at the positive electrode/anode $/ \mathrm{Na}^{+}$ions are reduced and $\mathrm{Cl}^{-}$ions are oxidized;

(Positive electrode/anode):

$2 \mathrm{Cl}^{-} \rightarrow \mathrm{Cl}_{2}+2 \mathrm{e}^{-} / \mathrm{Cl}^{-} \rightarrow \frac{1}{2} \mathrm{Cl}_{2}+\mathrm{e}^{-}$;

(Negative electrode/cathode)

$2 \mathrm{Na}^{+}+2 \mathrm{e}^{-} \rightarrow 2 \mathrm{Na} / \mathrm{Na}^{+}+\mathrm{e}^{-} \rightarrow \mathrm{Na}$;

Award [1 max] if equations not labelled or labelled wrong way round.

Allow e instead of $e^{-}$.

Penalize equilibrium sign or reversible arrows once only in parts (a) (ii) and (d) (ii).

(iii) Products: anode cuthode

oxygen at positive electrode and hydrogen at negative electrode;

moles of $\mathrm{Mg}=0.5 /$ mole ratio of $\mathrm{O}_{2}: \mathrm{H}_{2}$ is $1: 2$;

Can be implied by calculation.

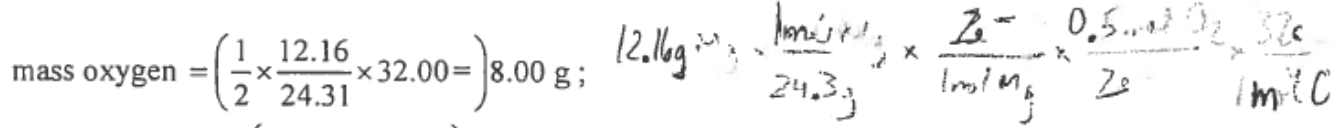

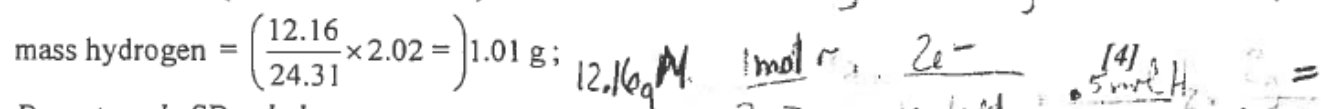

Do not apply SD rule here.

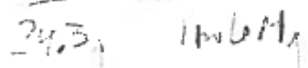

1
12

$\ln +1$ 